\title{
A Metallic Fuel Performance Benchmark Problem Based on the IFR-1 Experiment
}

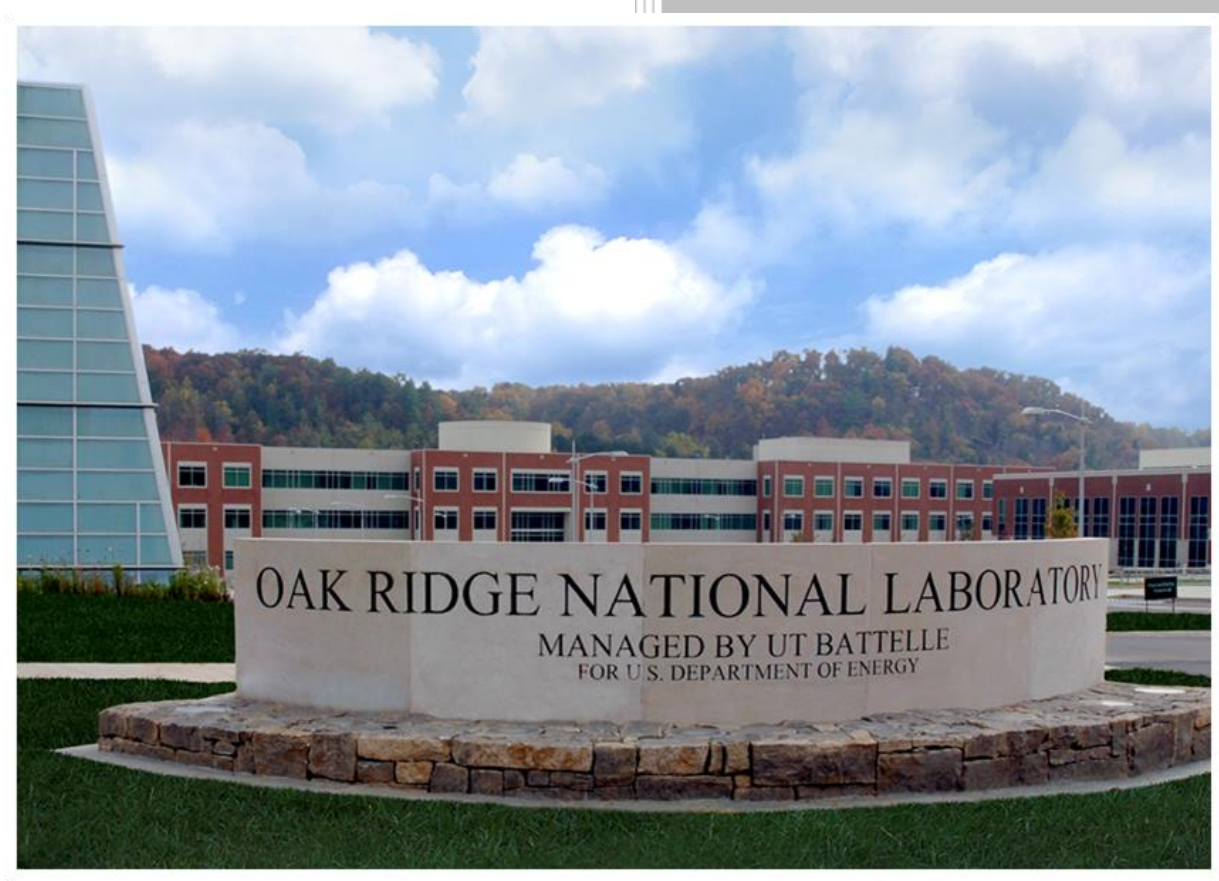

Approved for public release.

Distribution is unlimited.

lan Greenquist

Kaylee M. Cunningham

Jianwei Hu

Jeffrey J. Powers

June 2020 


\title{
DOCUMENT AVAILABILITY
}

Reports produced after January 1, 1996, are generally available free via US Department of Energy (DOE) SciTech Connect.

Website www.osti.gov

Reports produced before January 1,1996, may be purchased by members of the public from the following source:

\author{
National Technical Information Service \\ 5285 Port Royal Road \\ Springfield, VA 22161 \\ Telephone 703-605-6000 (1-800-553-6847) \\ TDD 703-487-4639 \\ Fax 703-605-6900 \\ E-mail info@ntis.gov \\ Website http://classic.ntis.gov/
}

Reports are available to DOE employees, DOE contractors, Energy Technology Data Exchange representatives, and International Nuclear Information System representatives from the following source:

Office of Scientific and Technical Information

PO Box 62

Oak Ridge, TN 37831

Telephone 865-576-8401

Fax 865-576-5728

E-mail reports@osti.gov

Website http://www.osti.gov/contact.html

This report was prepared as an account of work sponsored by an agency of the United States Government. Neither the United States Government nor any agency thereof, nor any of their employees, makes any warranty, express or implied, or assumes any legal liability or responsibility for the accuracy, completeness, or usefulness of any information, apparatus, product, or process disclosed, or represents that its use would not infringe privately owned rights. Reference herein to any specific commercial product, process, or service by trade name, trademark, manufacturer, or otherwise, does not necessarily constitute or imply its endorsement, recommendation, or favoring by the United States Government or any agency thereof. The views and opinions of authors expressed herein do not necessarily state or reflect those of the United States Government or any agency thereof. 
Reactor and Nuclear Systems Division

\title{
A METALLIC FUEL PERFORMANCE BENCHMARK PROBLEM BASED ON THE IFR-1 EXPERIMENT
}

\author{
Ian Greenquist* \\ Kaylee M. Cunningham** \\ Jianwei $\mathrm{Hu}^{*}$ \\ Jeffrey J. Powers*
}

*Oak Ridge National Laboratory

**University of Florida

May 2020

\author{
Prepared by \\ OAK RIDGE NATIONAL LABORATORY \\ Oak Ridge, TN 37831-6283 \\ managed by \\ UT-BATTELLE, LLC \\ for the \\ US DEPARTMENT OF ENERGY \\ under contract DE-AC05-00OR22725
}





\section{CONTENTS}

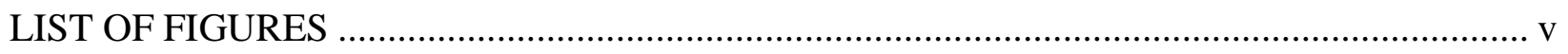

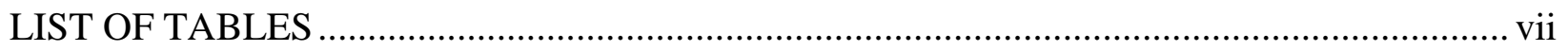

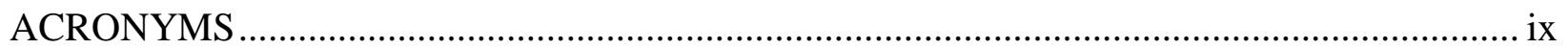

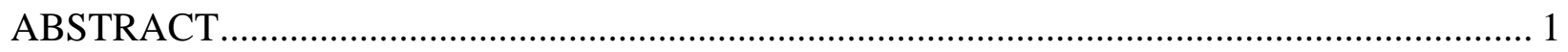

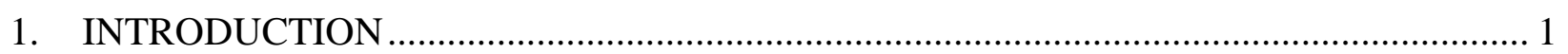

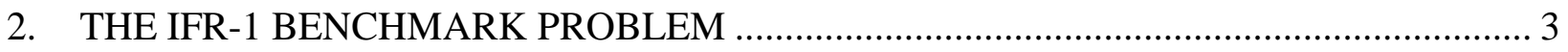

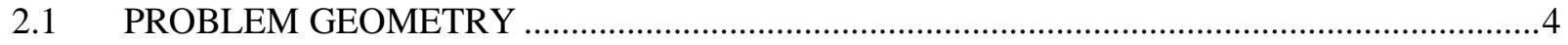

2.2 LINEAR HEAT RATE AND POWER HISTORY ..........................................................

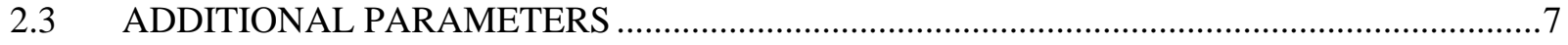

2.4 AVAILABLE DATA FOR COMPARISON …………..................................................

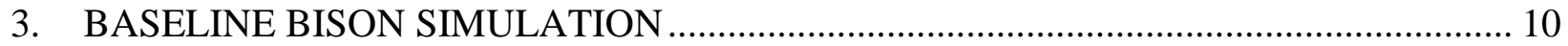

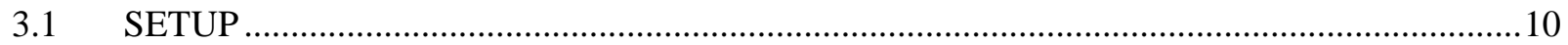

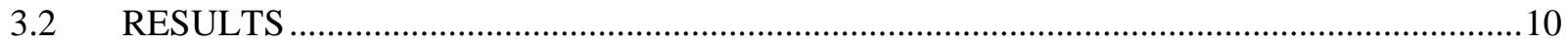

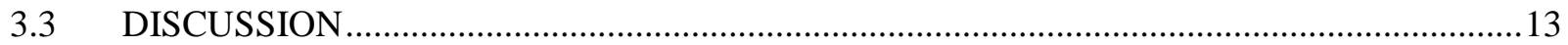

4. BISON SIMULATION WITH THE FRICTION GAP MODEL …………….................... 13

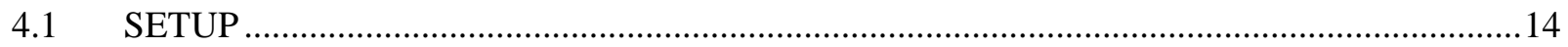

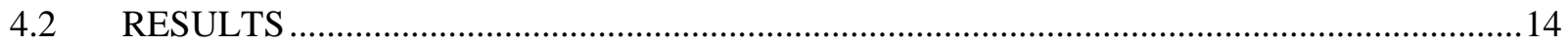

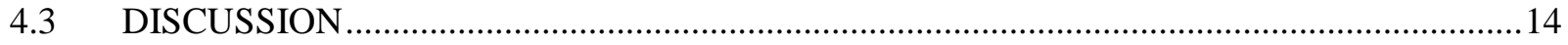

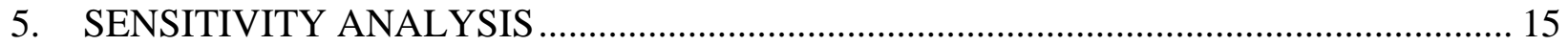

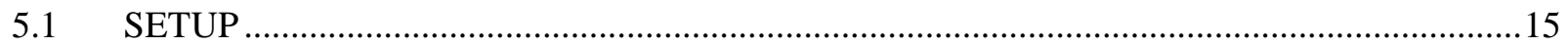

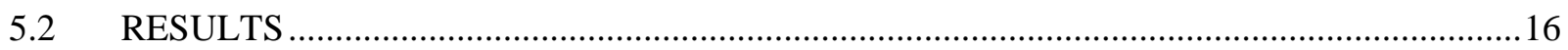

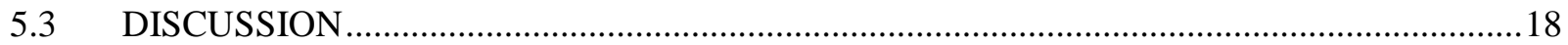

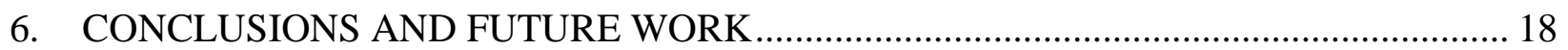

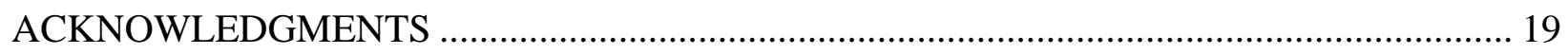

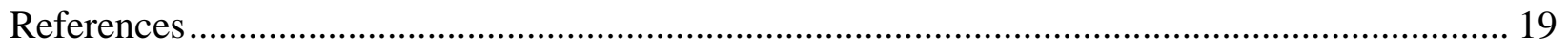

APPENDIX A. COMPARISONS OF INPUT PARAMETERS TO SIMULATION RESULTS DURING SENSITIVITY ANALYSIS ............................................................................... A-3 


\section{LIST OF FIGURES}

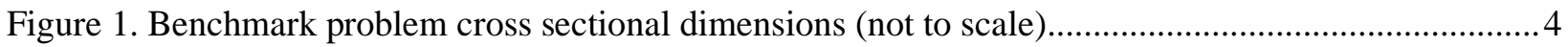

Figure 2. Comparison of the polynomial to the experimental LHR ................................................. 7

Figure 3. Temperature and displacement results of the BISON simulation............................................ 11

Figure 4. Comparison of BISON simulation results with experimental results ...................................... 12

Figure 5. Comparison of experimental radial growth at PIE and simulated radial growth at 600

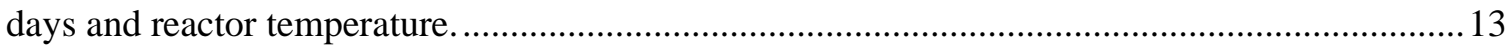

Figure 6. Comparison of BISON simulation results including friction to experimental results. ................ 14

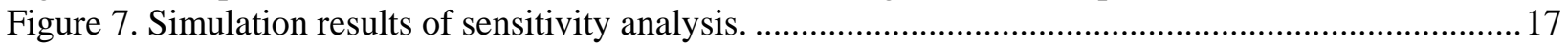

Figure 8. Distributions of the variables from the 200 BISON simulations shown in Figure 7. ................. 18

Figure 9. Comparison of input parameters and burnup results for the sensitivity analysis........................3

Figure 10. Comparison of input parameters and peak cladding temperature results for the

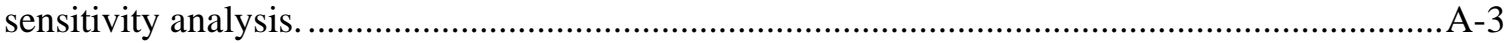

Figure 11. Comparison of input parameters and peak coolant temperature results for the

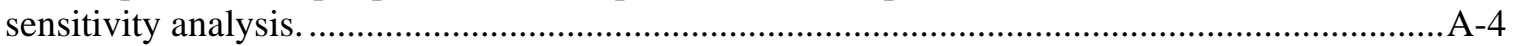

Figure 12. Comparison of input parameters and cladding radial growth results for the sensitivity

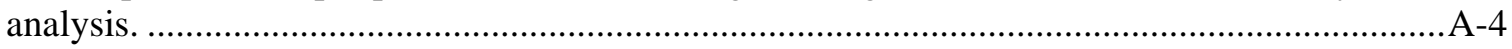

Figure 13. Comparison of input parameters and fuel axial growth for the sensitivity analysis. ..............A-5

Figure 14. Comparison of input parameters and FGR results for the sensitivity analysis. ........................ 


\section{LIST OF TABLES}

Table 1. Experiments available for potential metallic fuel benchmark problems ...................................... 3

Table 2. Average LHR history for benchmark with coolant inlet temperature peak burnup ......................6

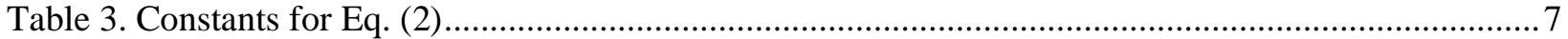

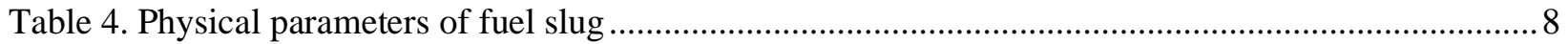

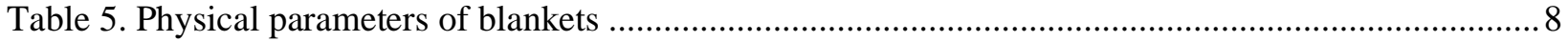

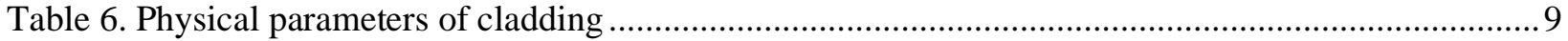

Table 7. Physical parameters of coolant and plenum ........................................................................... 


\section{ACRONYMS}

$\begin{array}{ll}\text { BOC } & \text { beginning of cycle } \\ \text { CTE } & \begin{array}{l}\text { coefficient of thermal expansion } \\ \text { DOS Department of Energy }\end{array} \\ \text { EBR-II } & \begin{array}{l}\text { Experimental Breeder Reactor II } \\ \text { effective full power day } \\ \text { EFPD }\end{array} \\ \text { EOC } & \text { end of cycle } \\ \text { fuel-cladding chemical interaction } \\ \text { FFTF } & \text { Fast flux Test Facility } \\ \text { FGR } & \text { fission gas release } \\ \text { IFR } & \text { Integral Fast Reactor } \\ \text { INL } & \text { Idaho National Laboratory } \\ \text { LHR } & \text { linear heat rate } \\ \text { ORNL } & \text { Oak Ridge National Laboratory } \\ \text { PIE } & \text { post-irradiation examination }\end{array}$




\begin{abstract}
Metallic nuclear fuels are an active area of research and development for use in advanced reactors. Robust, accurate metallic fuel performance models are necessary for the design, safety analysis, and licensing of such reactors. However, metallic fuel performance models require additional development; they are not as mature as ceramic fuel performance models. Oak Ridge National Laboratory (ORNL) has developed a benchmark problem based on the Integral Fast Reactor (IFR)-1 experiment to better gauge the accuracy of existing models, identify high-priority models for development, and quantify the improvements made by future model development.
\end{abstract}

This work included collection of all relevant information on the IFR-1 experiment and used it to develop the benchmark problem. The problem was simulated using the fuel performance code BISON, and the results were compared to post-irradiation examination data from the IFR-1 experiment. A sensitivity analysis was performed on the BISON model to determine the benchmark problem's sensitivity to uncertainty in the input parameters.

The results suggest that BISON's mechanical models require additional development. Plastic deformation was underpredicted in the cladding, and axial swelling was overpredicted in the fuel. These problems may be related. Furthermore, there was a bias in the temperature which may have been a result of uncertainty in the input parameters rather than an issue with the fuel performance models.

\title{
1. INTRODUCTION
}

$\mathrm{UO}_{2}$ is the dominant nuclear fuel worldwide: decades of research have gone into the development of fuel performance models for this ceramic fuel type. Far less research and development has been devoted to metallic fuel performance models than to their ceramic counterparts $[1,2,3]$. Now that the US Department of Energy (DOE) is considering using metallic fuels for a possible new test reactor [4, 5] and several private companies are pursuing metallic fuel designs [6], accurate metallic fuel performance models are necessary to aid in experiment design, reactor design, and safety qualification of commercial reactors. One way to gauge the accuracy of existing and future metallic fuel performance models is through the use of benchmark problems. Benchmark problems are fuel performance simulations of real experiments that compare the predicted results to the corresponding experimental results. Benchmark problems aid in the development of fuel performance models in several ways. First, they check the accuracy of existing models. Second, any inaccurate results can help identify high-priority models for development. Third, they can be used to quantify the improvements made by new or updated models.

This report details the development of a benchmark problem for $71 \mathrm{wt} \%$ uranium, $19 \mathrm{wt} \%$ plutonium, 10 $\mathrm{wt} \%$ zirconium (U-19Pu-10Zr) metallic fuel based on the IFR-1 experiment, which was the only full-size fuel assembly irradiated for the Integral Fast Reactor (IFR) concept. The IFR was a DOE-led reactor concept developed during the late 1980s and early 1990s. It was meant to commercialize the technology used in Experimental Breeder Reactor II (EBR-II), a sodium pool-type fast reactor [7]. Most experiments for the project were irradiated in EBR-II. However, the IFR concept used longer fuel pins than those used in EBR-II. Since a full-sized IFR fuel pin could not be irradiated in the EBR-II core, the IFR-1 
experiment was irradiated in the Fast Flux Test Facility (FFTF). The experiment was irradiated between September 1986 and October 1988 to a peak burnup of approximately 10 at\%. Researchers were interested in comparing the neutronic and mechanical effects of full-length pins with those seen in EBRII's shorter test pins.

The FFTF is a loop-type sodium-cooled fast-spectrum test reactor that operated between 1982 and 1992. It is located at the 400 area of the Hanford Site in Hanford, Washington [8]. Compared to reactors such as EBR-II, FFTF boasts a large experiment volume and transient testing capabilities [9].

Three main publications document the results of the IFR-1 experiment: a 1992 conference paper [10], a 2011 Idaho National Laboratory (INL) report [11], and a 2012 peer-reviewed journal article based on the 2011 report [12]. Of the three sources, the INL report [11] is the most comprehensive and therefore serves as the primary reference for this benchmark problem.

This work compiles all relevant available information on the FFTF reactor and the IFR-1 experiment to construct the benchmark problem. A baseline simulation of the benchmark problem was performed using the BISON fuel performance code. Additional physics in the form of friction were added, and the results were compared to the baseline model performance. Finally, a sensitivity analysis using the baseline model was used to determine which input parameters had the most effect on the simulation results.

BISON is a fuel performance code under active development at INL $[13,14]$. Since it is under development, this report is not meant as a validation or evaluation of the BISON code or the models used in it. Rather, this benchmark problem is intended to guide the development of BISON and metallic fuel performance models. This report builds on earlier work documenting development of this benchmark problem [15], improving some of the boundary conditions and power history information and drawing on BISON's new mesh options and D9 cladding model to improve accuracy.

Just as no individual experiment can capture all relevant fuels, claddings, and operating conditions, no benchmark problem can test all relevant fuel performance models. A wide array of benchmark problems will be necessary to test the full range of fuel performance models. Table 1 lists historic metallic fuel experiments that could potentially be used to develop benchmark problems, along with the maximum burnup achieved in each experiment. The experiments are sorted by cladding material and plutonium content. By developing benchmark problems that cover the full range of plutonium contents, cladding types, and burnups, a more complete evaluation of fuel performance models could be possible. 
Table 1. Experiments available for potential metallic fuel benchmark problems

\begin{tabular}{|c|c|c|c|c|c|c|}
\hline \multirow{2}{*}{$\begin{array}{c}\text { Pu } \\
\text { content } \\
(w t \%)\end{array}$} & \multicolumn{6}{|c|}{ Cladding material (peak burnup [at\%]) } \\
\hline & \multicolumn{2}{|c|}{ D9 } & \multicolumn{2}{|c|}{ HT9 } & \multicolumn{2}{|c|}{$316 \mathrm{SS}$} \\
\hline \multirow{18}{*}{0} & X419 & $(11.9)$ & X429 & $(14.4)$ & X423 & $(4.9)$ \\
\hline & $\mathrm{X} 420$ & $(18.4)$ & $\mathrm{X} 430$ & $(11.5)$ & X429 & $(14.4)$ \\
\hline & $\mathrm{X} 421$ & $(17.1)$ & $\mathrm{X} 431 \mathrm{a}$ & $(3.9)$ & X483 & $(14.4)$ \\
\hline & $\mathrm{X} 425$ & (19.3) & $\mathrm{X} 432 \mathrm{a}$ & $(4.5)$ & $\mathrm{X} 484$ & $(11.7)$ \\
\hline & $\mathrm{X} 435$ & $(19.8)$ & X447 & $(10)$ & $\mathrm{X} 485$ & $(10.5)$ \\
\hline & $\mathrm{X} 436$ & $(9.3)$ & $\mathrm{X} 448$ & $(14.6)$ & $\mathrm{X} 486$ & $(13.9)$ \\
\hline & $\mathrm{X} 437$ & (10.3) & X449 & (11.3) & & \\
\hline & $\mathrm{X} 438$ & $(9.9)$ & $\mathrm{X} 450$ & (10.2) & & \\
\hline & $\mathrm{X} 452$ & (6.1) & $\mathrm{X} 451$ & (13.7) & & \\
\hline & X453 & $(8.5)$ & X496 & $(8.3)$ & & \\
\hline & X454 & $(8.3)$ & X501 & (7.6) & & \\
\hline & X455 & (10.3) & MFF1A & (4.1) & & \\
\hline & X482 & (14.4) & MFF-1 & (10.2) & & \\
\hline & IFR-1 & (10) & MFF-2 & (15.3) & & \\
\hline & M7 & $(9.8)$ & MFF-3 & (14.7) & & \\
\hline & & & MFF-4 & (14.4) & & \\
\hline & & & MFF-5 & (10.8) & & \\
\hline & & & MFF-6 & (15.1) & & \\
\hline \multirow{5}{*}{$0.1-10$} & X419 & (11.9) & X429 & (14.4) & $\mathrm{X} 423$ & $(4.9)$ \\
\hline & X420 & (18.4) & & & X429 & (14.4) \\
\hline & X421 & (17.1) & & & $X Y-27$ & (6) \\
\hline & X425 & (19.3) & & & & \\
\hline & IFR-1 & (10) & & & & \\
\hline \multirow{11}{*}{$10.1-20$} & X419 & (11.9) & X429 & (14.4) & $\mathrm{X} 423$ & $(4.9)$ \\
\hline & $\mathrm{X} 420$ & (18.4) & $\mathrm{X} 430$ & (11.5) & X429 & (14.4) \\
\hline & X421 & (17.1) & X441 & (12.7) & $X Y-24$ & $(7.6)$ \\
\hline & X425 & (19.3) & X489 & $(5.4)$ & & \\
\hline & $\mathrm{X} 441_{\mathrm{a}}$ & (12.7) & & & & \\
\hline & X481 & (10) & & & & \\
\hline & X482 & (14.4) & & & & \\
\hline & IFR-1 & (10) & & & & \\
\hline & M5 & (1.9) & & & & \\
\hline & M6 & (5.3) & & & & \\
\hline & M7 & (9.8) & & & & \\
\hline \multirow{3}{*}{$20.1+$} & & & $\mathrm{X} 430$ & (11.5) & X423 & $(4.9)$ \\
\hline & & & X489 & $(5.4)$ & & \\
\hline & & & $\mathrm{X} 501 \mathrm{~b}$ & $(7.6)$ & & \\
\hline
\end{tabular}

Metallic fuels of composition U-XPu-10Zr, sorted by Pu weight percent and the cladding used $[27,3]$. The peak burnup achieved by the experiment is also shown.

$a$ : Experiment also varied the $\mathrm{Zr}$ content

$b$ : Fuel contained additional alloying elements

\section{THE IFR-1 BENCHMARK PROBLEM}

Multiple measurements were made of the IFR-1 experiment, but not every measurement was made for every pin. To maximize the amount of data available for comparison, the problem was developed using data from multiple U-19Pu-10Zr pins, and it was assumed that the pins behaved similarly. The benchmark pin was assumed to represent a generic average pin rather than any individual pin. While this assumption was reasonable, it likely introduced some error into the problem setup and the results. 
The INL report contains some inconsistencies in the recorded data [11]. Some data are mislabeled, and others are missing. Therefore, the benchmark problem in the current work represents the most complete reconstruction possible based on the information currently available. However, the problem may require updates if additional information becomes available in the future.

\subsection{PROBLEM GEOMETRY}

The IFR-1 test assembly consisted of 169 fuel pins in a hexagonal assembly, with 8 pins per side. Of the pins, 18 contained U-19Pu-10Zr alloy fuel, 19 contained U-8Pu-10Zr alloy fuel, and the remainder contained $\mathrm{U}-10 \mathrm{Zr}$ alloy fuel. The uranium enrichment was adjusted for each alloy to maintain the same approximate heat generation rate. All of the pins were clad in 20\% cold-worked D9 stainless steel [16] and were wrapped in $1.37 \mathrm{~mm}$ diameter D9 wire that served as a spacer between pins and as a turbulence generator to improve mixing/thermal transport of the sodium coolant.

The active fuel column for each pin was $914 \mathrm{~mm}$ long and consisted of three uniform slugs, each of which was $4.98 \mathrm{~mm}$ in diameter. Two blanket regions, one above and one below the fuel column, consisted of U-Zr blanket slugs $165 \mathrm{~mm}$ long and $4.98 \mathrm{~mm}$ in diameter. The uranium in the blankets was depleted, with a $235 \mathrm{U}$ concentration below that of natural uranium. The cladding was $0.56 \mathrm{~mm}$ thick, with an outer diameter of $6.86 \mathrm{~mm}$, and the pins had a total as-manufactured length of $2377.4 \mathrm{~mm}$. The INL report [11] includes images of the tops of the fuel pins showing their machined tips used for handling. However, because the dimensions of the tips are not given, and no information is provided about the bottom end plug, there is some uncertainty in the plenum volume.

The same dimensions are used as much as possible for the benchmark problem. The top and bottom end plug thickness is assumed to be $3.0 \mathrm{~mm}$, and the bottom blanket slug sits $0.4 \mathrm{~mm}$ above the bottom plug. A sensitivity analysis showed that these dimensions do not significantly affect the results. The problem geometry is shown in Figure 1. For the BISON simulation presented in Section 3, a 2D axisymmetric mesh was used instead of the full 3D fuel pin. This is much more computationally efficient and should not significantly impact the results since no azimuthal variations were known or modeled.

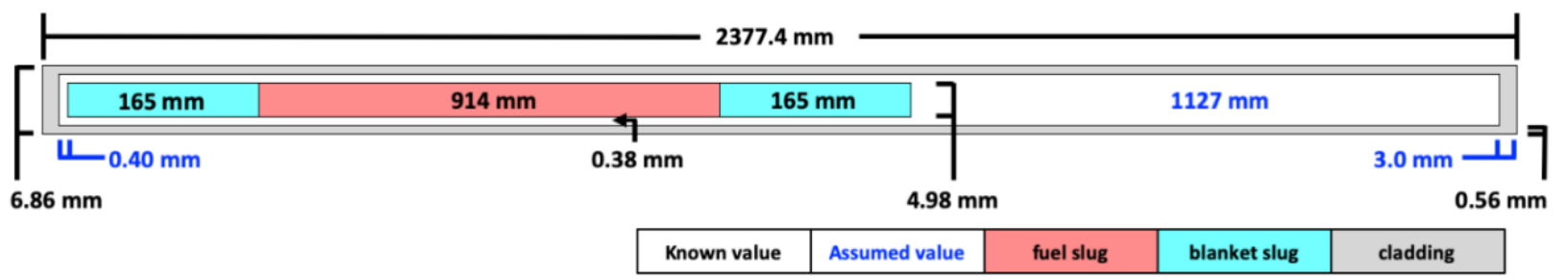

Figure 1. Benchmark problem cross sectional dimensions (not to scale). Black text indicates values from the INL report [11], and blue text indicates values that had to be assumed or inferred.

In a report by Cunningham et al. [15], the blankets were neglected because BISON did not have a good system for distinguishing between different regions in the fuel slug. However, recent additions to the MOOSE framework - the framework upon which BISON is built - enabled inclusion of the blankets in this work.

\subsection{LINEAR HEAT RATE AND POWER HISTORY}

The linear heat rate (LHR) profile is the primary input into fuel performance simulations. It is vital to ensure that the LHR is as accurate as possible. As commonly done in fuel performance analysis, the LHR 
is separated into two functions: the time dependent average LHR, $\overline{L H R}(t)$, and the spatially dependent axial peaking factor, $p(z)$ :

$$
\operatorname{LHR}(t, z)=\overline{L H R}(t) p(z)
$$

where the variable $t$ represents time in seconds, and $z$ represents the axial position in meters; $p(z)$ has the additional constraint that the average peaking factor over the length of the fuel must be equal to 1 . In reality, $p(z)$ changes over time, but the INL report [11] only calculated a single profile, so that profile is assumed constant in this work.

The IFR-1 experiment ran over the course of six FFTF operating cycles: 9A, 9B, 9C, 10A-1, 10A-2, and 10B. The INL report [11] records the equivalent full-power days (EFPDs) of each cycle and the average LHRs at beginning of cycle (BOC) and end of cycle (EOC). The only exception is that no LHR was recorded for 10A-1 EOC. These average LHRs were recorded for multiple pins. These records were used to derive a power history by assuming that each EFPD corresponded to exactly 24 hours, and the average LHR among the U-19Pu-10Zr pins was calculated at each point. The power history and some other timedependent values are given in Table 2. The time is given in both days and seconds, since seconds are the time unit of the simulations, but days are easier to read. $\overline{L H R}(t)$ was determined by linearly interpolating between the provided LHR values.

One additional hour was added to the beginning of the simulation to allow time for the LHR and coolant temperature to ramp up to operating conditions. This reduced the shock on the pin by letting thermal expansion happen gradually. At the end of the experiment, another one-hour ramp time was added to reduce the pin's LHR to $0.1 \%$ of its last operating LHR. A one-day period was added to reduce the coolant temperature, and finally, another day was allowed for the simulation to reach equilibrium before post-irradiation examination (PIE).

The INL report [11] gives detailed burnup calculations for one of the U-19Pu-10Zr fuel pins at the end of each cycle except 10A-2 and 10B. These are also included in Table 2. For cycle 10B, recorded peak burnups for each pin were averaged to obtain an average burnup. No burnup data were found in the INL report [11] for cycle 10A-2. 
Table 2. Average LHR history for benchmark with coolant inlet temperature peak burnup

\begin{tabular}{|c|c|c|c|c|c|}
\hline Cycle point & $\begin{array}{l}\text { Timea } \\
\text { (days) }\end{array}$ & Time (s) & $\begin{array}{c}\text { Average } \\
\text { LHR (W/m) }\end{array}$ & $\begin{array}{c}\text { Coolant } \\
\text { temperature (K) }\end{array}$ & $\begin{array}{c}\text { Peak } \\
\text { burnup } \\
\text { (at\%) }\end{array}$ \\
\hline Startup & 0.00 & 0 & 0.0 & 298 & \\
\hline 9A BOC & 0.04 & 3,600 & $39,559.2$ & 633 & 0 \\
\hline 9A EOC & 137.74 & $11,900,880$ & $36,501.4$ & 633 & 2.61 \\
\hline 9B BOC & 137.78 & $11,904,480$ & $36,005.5$ & 633 & \\
\hline 9B EOC & 244.18 & $21,097,440$ & $34,600.6$ & 633 & 4.44 \\
\hline 9С BOC & 244.23 & $21,101,040$ & $36,088.2$ & 633 & \\
\hline 9C EOC & 341.93 & $29,542,320$ & $34,683.2$ & 633 & 6.12 \\
\hline $10 \mathrm{~A}-1 \mathrm{BOC}$ & 341.97 & $29,545,920$ & $29,438.7$ & 633 & \\
\hline $10 \mathrm{~A}-1 \mathrm{EOC}$ & 408.27 & $35,274,240$ & $29,438.7 \mathrm{~b}$ & 633 & 7.84 \\
\hline $10 \mathrm{~A}-2 \mathrm{BOC}$ & 408.31 & $35,277,840$ & $31,515.2$ & 633 & \\
\hline $10 \mathrm{~A}-2 \mathrm{EOC}$ & 493.81 & $42,665,040$ & $24,776.2$ & 633 & \\
\hline 10B BOC & 493.85 & $42,668,640$ & $30,055.1$ & 633 & \\
\hline 10B EOC & 620.55 & $53,615,520$ & $30,110.2$ & 633 & $9.50_{\mathrm{c}}$ \\
\hline Shutdownd & 620.59 & $53,619,120$ & 30.11 & 633 & \\
\hline Cooldownd & 621.59 & $53,705,520$ & 30.11 & 305 & \\
\hline $\mathrm{PIE}_{\mathrm{d}}$ & 622.59 & $53,791,920$ & 30.11 & 305 & \\
\hline
\end{tabular}

$\mathrm{BOC}=$ beginning of cycle $; \mathrm{EOC}=$ end of cycle; $\mathrm{PIE}=$ post-irradiation examination

$a$ : Time was calculated using recorded EFPDs with assumed one-hour transition periods between cycles. $b$ : No power level appears to have been recorded in the INL report [11]; this work assumes the power level remained constant during this step.

$c$ : This value was calculated separately from the other burnup values.

$d$ : Shutdown, cooldown, and PIE steps provide time for the fuel and cladding to transition to a more reasonable PIE temperature. The LHR during this period was assumed to be $0.1 \%$ of the last operating LHR.

The axial peaking factor $p(z)$ in the fuel slug was determined by fitting a fourth-order polynomial function to the beginning-of-life axial power curve specified in the INL report [11] (p. 25, Fig. 20); however, the power of the blanket regions is not calculated in the INL report [11]. This work approximates the power by using the isotopic gamma scan of ${ }_{106} \mathrm{Rh}$ from the INL report (p. 7, Fig. 1). Linear equations were fit to the blanket regions, multiplied by burnup, and then combined with the slug polynomial to yield the piecewise equation:

$$
\begin{aligned}
p(z)= & \left\{\begin{array}{cl}
\left(m_{b} z+b_{b}\right) b u^{*}, & 0 \leq z<z_{b} \\
a_{0}+a_{1} z_{f}+a_{2} z_{f}^{2}+a_{3} z_{f}^{3}+a_{4} z_{f}^{4}, & z_{b} \leq z \leq z_{t} \\
\left(m_{t} z+b_{t}\right) b u^{*}, & z_{t}<z \leq 1.244
\end{array}\right. \\
& z_{f}=z-z_{b}, \quad b u^{*}=\frac{b u}{b u_{r e f}},
\end{aligned}
$$

where $b u$ is the peak burnup, $b u^{*}$ is the relative burnup compared to a reference burnup, $b u_{r e f}>0, z_{b}$ is the height of the bottom blanket, and $z_{t}$ is the combined height of the bottom blanket and fuel slug. This form allows the blanket power to increase as it breeds fuels. The constant values-including the $a, b$, and $m$ fitting parameters - are given in Table 3. Equation (2) can be compared to the axial power curve by choosing a reference burnup and average LHR. This is shown in Figure 2, where $\overline{L H R}=37,112 \mathrm{~W}$ m-1 and $b u^{*}=1$. 
Table 3. Constants for Eq. (2)

\begin{tabular}{cc}
\hline Constant & Value \\
\hline$a_{0}$ & 0.68687 \\
$a_{1}$ & 2.6352 \\
$a_{2}$ & -3.20026 \\
$a_{3}$ & $1.35 \times 10-5$ \\
$a_{4}$ & $2.69 \times 10-5$ \\
$b_{b}$ & 0.084 \\
$b_{t}$ & 0.416 \\
$b u_{r e f}$ & $5 \mathrm{at} \%$ \\
$m_{b}$ & $0.279 \mathrm{~m}-1$ \\
$m_{t}$ & $-0.301 \mathrm{~m}-1$ \\
$z_{b}$ & $0.165 \mathrm{~m}$ \\
$z_{t}$ & $1.079 \mathrm{~m}$ \\
\hline
\end{tabular}

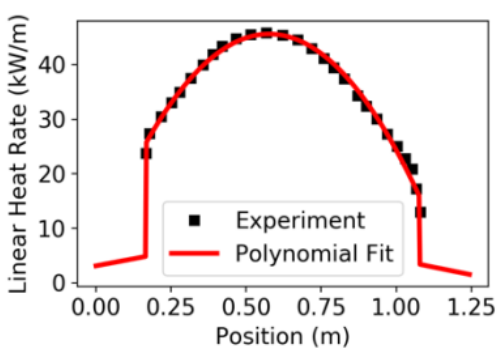

Figure 2. Comparison of the polynomial to the experimental LHR. The average LHR is $37,112 \mathrm{~W} \mathrm{~m}-1$ and the burnup is 5 at $\%$. The peaking factor function is the polynomial shown here divided by the average LHR.

Note that Eq. (2) has an average value of 1 only within the fuel region. The INL report [11] does not specify whether the blankets were considered in the LHR calculations, so for simplicity, this work assumes they were not. At 10 at\% burnup, the blankets increase $L H R(t, z)$ by $6 \%$ over $\overline{L H R}(t)$.

\subsection{ADDITIONAL PARAMETERS}

The BISON metallic fuel performance model input parameters are separated into the following groups: fuel properties, blanket properties, cladding properties, and coolant and plenum properties. The parameters are listed in Tables 4-7. Most are taken from the literature about FFTF and metallic fuel systems. Those that are not available directly from the literature are explained in more detail below. In addition to the properties shown, every material also has a stress-free temperature, which BISON uses as the temperature at which no dimensional change from thermal expansion has occurred. To maintain the room temperature dimensions, the stress-free temperature for each material is set to $295 \mathrm{~K}$.

The physical and mechanical properties of the U-19Pu-10Zr fuel are given in Table 4. The anisotropic swelling factor, fission gas bubble number density, and fast flux factor are not directly available in the literature. The anisotropic swelling factor is a unitless fitting parameter that controls the relative rates of axial and radial swelling in the fuel. It can have any value between -1 and 1 , where a value of -1 indicates that $100 \%$ of the swelling occurs in the axial direction, and a value of 1 means that $100 \%$ of the swelling occurs in the radial direction. A value of 0 corresponds to anisotropic swelling. U-Pu-Zr swells preferentially in the radial direction [17], so this work assumes a value of 0.5 , which corresponds to $75 \%$ of the swelling occurring in the radial direction. 
Table 4. Physical parameters of fuel slug

\begin{tabular}{lcc}
\hline Parameter & Value & Reference \\
\hline Anisotropic swelling factor & 0.5 & \\
Atom fraction of $\mathrm{Pu}$ & 0.16 & [17] p. 134 \\
Atom fraction of $\mathrm{Zr}$ & 0.226 & {$[17] \mathrm{p} .134$} \\
Average energy per fission & $3.159 \times 10-11 \mathrm{~J}$ & {$[11] \mathrm{pp} .74-83$} \\
Coefficient of thermal expansion (CTE) & $17.3 \times 10-6 \mathrm{~K}-1$ & {$[17] \mathrm{p} .132$} \\
Density & $15,800 \mathrm{~kg} \mathrm{~m}-3$ & [17] p. 134 \\
Fast flux factor & $8.64 \times 1014 \mathrm{n} \mathrm{W}-1 \mathrm{~m}-1 \mathrm{~s}-1$ & \\
\hline
\end{tabular}

The fast flux factor is the ratio of fast neutron flux ( $\mathrm{n} \mathrm{m-2} \mathrm{s-1)} \mathrm{to} \mathrm{LHR} \mathrm{(W} \mathrm{m-1).} \mathrm{This} \mathrm{is} \mathrm{calculated} \mathrm{in} \mathrm{the}$ same manner as that used by Cunningham et al. [15]. The total fast neutron fluence is $15.4 \times 10_{26} \mathrm{n} \mathrm{m}-2$ [11] (p. 2). The total time spent in the reactor is 620.55 days (Table 2). Dividing these values gives an average fast neutron flux of $2.87 \times 10_{19} \mathrm{n} \mathrm{m}-2 \mathrm{~s}-1$. Table 2 also gives the time-averaged LHR as 33,241 W $\mathrm{m}-1$. Dividing the average fast neutron flux by the average LHR gives the fast flux factor shown in Table 4.

BISON also requires several parameters that feed into the fission gas release (FGR) model. For this work, the values are taken from training materials presented by Casagranda [18], which represent an empirical fit to the data in Pahl and Wisner [19].

The physical properties of the blankets are given in Table 5. All properties come from the Janney's "Metallic Fuels Handbook" [17], but the coefficient of thermal expansion (CTE) requires additional calculations. Equation (28) in the handbook [17] (p. 45,) is the nonlinear thermal expansion equation:

$$
\frac{\Delta L}{L_{0}}[\%]=-0.424+1.685 \times 10^{-3} T-1.052 \times 10^{6} T^{2}+1.115 \times 10^{-9} T^{3},
$$

where $T$ is the temperature ( $293 \mathrm{~K} \leq T \leq 900 \mathrm{~K}$ ), $L_{0}$ is the original length, and $\Delta L$ is the change in length. However, the thermal expansion model in BISON requires a constant CTE, so Eq. (3) above is linearized to:

$$
\frac{\Delta L}{L_{0}}[-]=16.6 \times 10^{-6} T-5.31 \times 10^{-3}
$$

Note that Eq. (4) returns a fraction rather than a percent. The CTE in Table 5 is the slope of Eq. (4).

Table 5. Physical parameters of blankets

\begin{tabular}{lcc}
\hline Parameter & Value & Reference \\
\hline Atom fraction of Zr & 0.225 & [17] p. 27 \\
CTE & $16.6 \times 10-6 \mathrm{~K}-1$ & \\
Density & $16,310 \mathrm{~kg} \mathrm{~m}_{-3}$ & [17] p. 50 \\
\hline
\end{tabular}

The physical and mechanical properties of the D9 cladding are given in Table 6. Once again, most values are taken directly from the literature, but the CTE has to be approximated from a nonlinear equation. The handbook by Hofman et al. [16] (E.1.2.2) gives the thermal expansion of D9 as:

$$
\frac{\Delta L}{L_{0}}[\%]=0.72549-0.12875 T^{\frac{1}{2}}+5.1890 \times 10^{-3} T-5.0431 \times 10^{-7} T^{2},
$$


where $293 \mathrm{~K} \leq T \leq 1050 \mathrm{~K}$. The linear approximation to Eq. (5) is

$$
\frac{\Delta L}{L_{0}}[-]=1.9 \times 10^{-5} \mathrm{~T}-6.37 \times 10^{-3} \text {. }
$$

Table 6. Physical parameters of cladding

\begin{tabular}{lcc}
\hline Parameter & Value & Reference \\
\hline Density & $7,761 \mathrm{~kg} \mathrm{~m}-3$ & {$[16] \mathrm{E} .1 .1 .6$} \\
CTE & $1.9 \times 10-5 \mathrm{~K}-1$ & \\
Poisson's ratio & 0.35 & {$[16] \mathrm{E} .1 .1 .6$} \\
Young's modulus & $1.645 \times 1011 \mathrm{~Pa}$ & {$[16]$ E.1.1.6 } \\
\hline
\end{tabular}

In addition to the parameters listed, some thermal properties of the fuel, blankets, and cladding are determined by internal BISON models $[20,14]$. In the fuel, the specific heat is calculated using the Savage model [21], and the thermal conductivity uses a modified form of the Kim equation [20, 22]. In Cunningham et al., [15], models for HT9 cladding were used because BISON did not include D9 models. However, BISON developers recently added D9 models, so improved results are now possible.

Properties of the sodium found in the coolant and plenum are given in Table 7. The initial plenum pressure is not included in the INL report [11], so this work assumes a reasonable value that is slightly sub-atmospheric and that is representative of the glovebox fabrication used in the IFR-1 pins. The coolant inlet mass flux is based on the coolant velocity and density as it enters the core. The coolant velocity in the center region of FFTF is $7.01 \mathrm{~m} \mathrm{~s}-1$ [9] (pp. 3-27). The density is calculated using Eq. (1) in the work by Fink and Liebowitz Ref. [23] (p. 86) for the coolant inlet temperature (Table 2). This gives a density of $866.9 \mathrm{~kg} \mathrm{~m}-3$. Multiplying the velocity by the density gives the mass flux listed in Table 7 .

Table 7. Physical parameters of coolant and plenum

\begin{tabular}{lcl}
\hline Parameter & Value & \multicolumn{1}{c}{ Reference } \\
\hline Coolant inlet mass flux & $6,079 \mathrm{~kg} \mathrm{~m}-2 \mathrm{~s}-1$ & \\
Coolant inlet pressure & $1,018,327 \mathrm{~Pa}$ & {$[9] \mathrm{pp} .2-10$} \\
Gap thermal conductivity & $61 \mathrm{~W} \mathrm{~m}-1 \mathrm{~K}-1$ & {$[23]$} \\
Plenum pressure & $84,000 \mathrm{~Pa}^{-1}$ & \\
Rod pitcha & $8.23 \times 10-3 \mathrm{~m}$ & {$[11] \mathrm{p} .2$} \\
\hline
\end{tabular}

$a$ : Equal to the pin diameter plus spacing wire diameter

\subsection{AVAILABLE DATA FOR COMPARISON}

The goal of this work is to compare the experimental data to the simulation results as much as possible. To do this, it is necessary to determine which data were measured and which of those measurements can be replicated by BISON. Seven measurements were identified which can be directly compared between the experimental data and the simulation results:

a) peak burnup at the end of most cycles,

b) peak cladding temperature at the beginning and end of each cycle,

c) coolant outlet temperature during cycle 9A (the only cycle for which the INL report [11] included these data),

d) cladding radial growth at the time of PIE, 
e) cladding axial growth at the time of PIE,

f) fuel axial growth at the time of PIE, and

g) fission gas release at the time of PIE.

These comparisons are made in Section 3.

The INL report [11] also includes PIE measurements for axial isotropic distributions, radial constituent redistribution, sodium penetration, and pin bowing. At the time of this work, however, BISON does not produce results that can be compared to these data. There are also many other quantities that BISON can calculate that were not measured during the experiment, such as stresses in the fuel and cladding, fuel temperatures, and the quantity of fission gas produced. Given these mismatches in available data from experiments and simulations, the measurements listed above appear to be the only ones in the experiment that can be reliably replicated by BISON.

\section{BASELINE BISON SIMULATION}

Metallic fuel performance models in BISON are under active development. The results in this section are not meant to validate BISON code or to comment on the accuracy of future BISON versions. They are meant to quantify the accuracy of current models and to identify areas that need improvements in the near future.

BISON is continually updated via Git. Simulations in this section and Section 4 are based on the BISON version from February 25, 2020, git commit debab342bd833d5a58fb87565ea9d9ded115fead.

\subsection{SETUP}

Additional discussion is warranted about some of the simulation-specific concerns that go into the benchmark problem, such as variables, boundary conditions, and numerical techniques. The primary simulation variables are temperature and displacements. Displacement is the difference between an node's current location and its initial location in radial and axial directions. Other parameters of interest such as burnup, porosity, and FGR are calculated as auxiliary variables or through postprocessing.

The initial conditions were a uniform temperature of $295 \mathrm{~K}$ and zero displacements. The boundary condition for radial displacement was a zero-value Dirichlet condition at the axial line of symmetry (fuel centerline). The boundary conditions for axial displacement were zero-value Dirichlet conditions at the bottom of the fuel and cladding meshes. The primary boundary condition for temperature was a zero-flux Neumann condition at the axial line of symmetry. There were also boundary conditions that controlled heat convection from the fuel to the plenum, from the plenum to the cladding, and from the cladding to the coolant. This section accounts for the fuel/cladding contact using a frictionless contact model [24], which is the most numerically stable [14] model. In the work described in Section 4, a frictional contact model is used.

\subsection{RESULTS}

The temperature and displacement results are shown in Figure 3. The color represents the temperature, and the displacements are shown as the mesh dimensions change. To make the mesh easier to view, it has been compressed by a factor of 50 in the axial direction. The blankets are easily distinguished as the regions at the top and bottom of the fuel with lower temperatures and lower radial growth. 


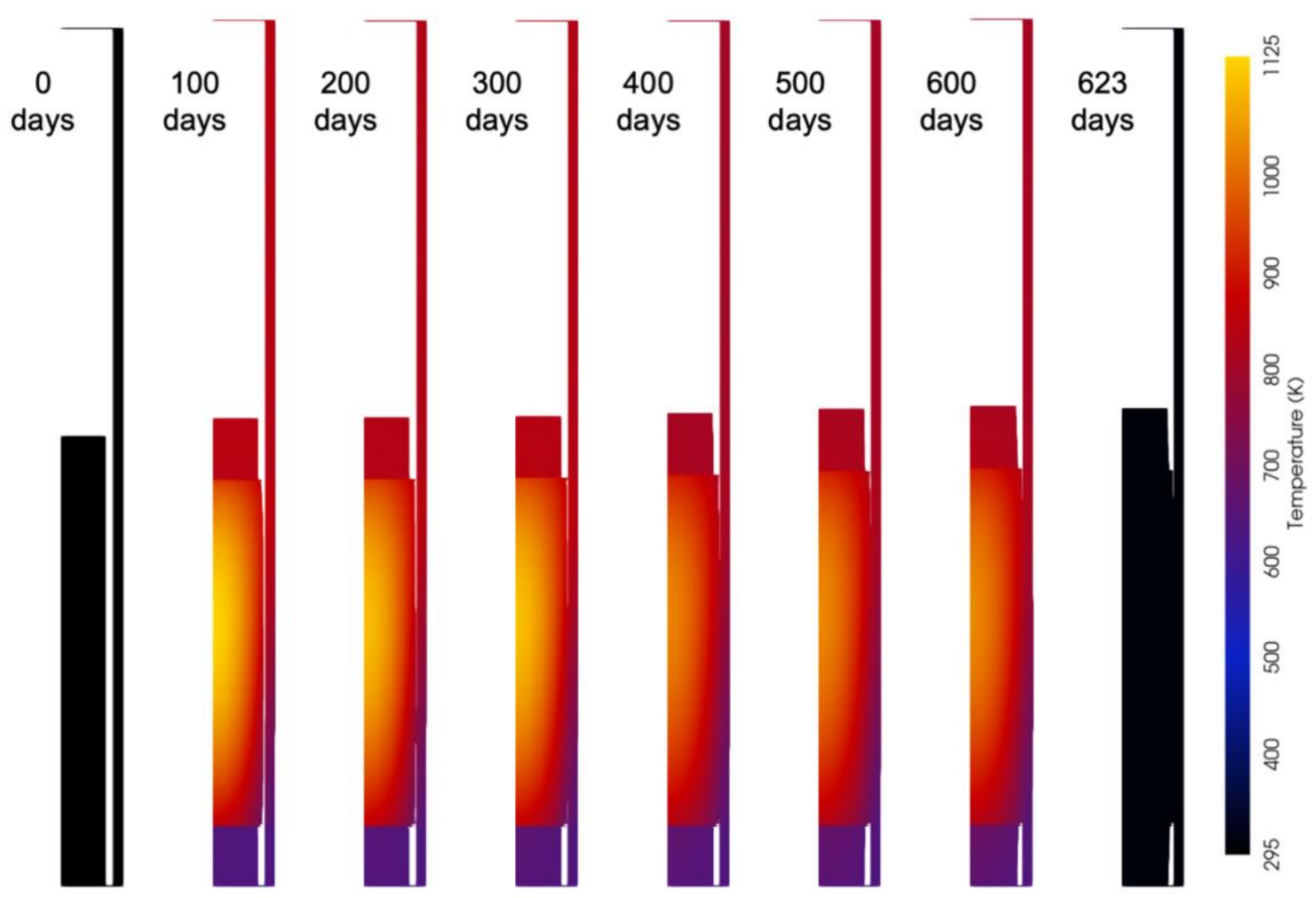

Figure 3. Temperature and displacement results of the BISON simulation. The mesh has been compressed by a factor of 50 in the axial direction to make it easier to view. The simulation time is given near the top of each image.

Color indicates temperature. Displacements are shown through dimensional changes of the mesh.

Figure 4 shows the seven comparisons between the simulation and experimental data specified in Section 2.4. Plot a shows the burnup during the experiment, which is as accurate as can be expected.

Plots $\mathrm{b}$ and $\mathrm{c}$ show the peak cladding temperature and the coolant outlet temperature. The INL report [11] states that during the experiment, the coolant outlet temperature was measured directly. However, the peak cladding temperature was not measured but was approximated by adding $40 \mathrm{~K}$ to the coolant outlet temperature. However, in cycle $9 \mathrm{~A}$, the two experimental temperatures vary by $32 \mathrm{~K}$. The reason for this discrepancy is not immediately clear.

The BISON-predicted temperatures are higher than the experimental temperatures during the entire simulation. The simulated peak cladding temperature is on average $43 \mathrm{~K}$ higher than the experimental values. In the case of the coolant outlet temperature, the simulation temperature is about $42 \mathrm{~K}$ higher than the experimental temperature. This suggests a consistent bias between the BISON model and comparison temperature. This may indicate a problem with the model, but it could also reflect problems with assumptions or input parameters in this work. This possibility is examined more closely in Section 5. 

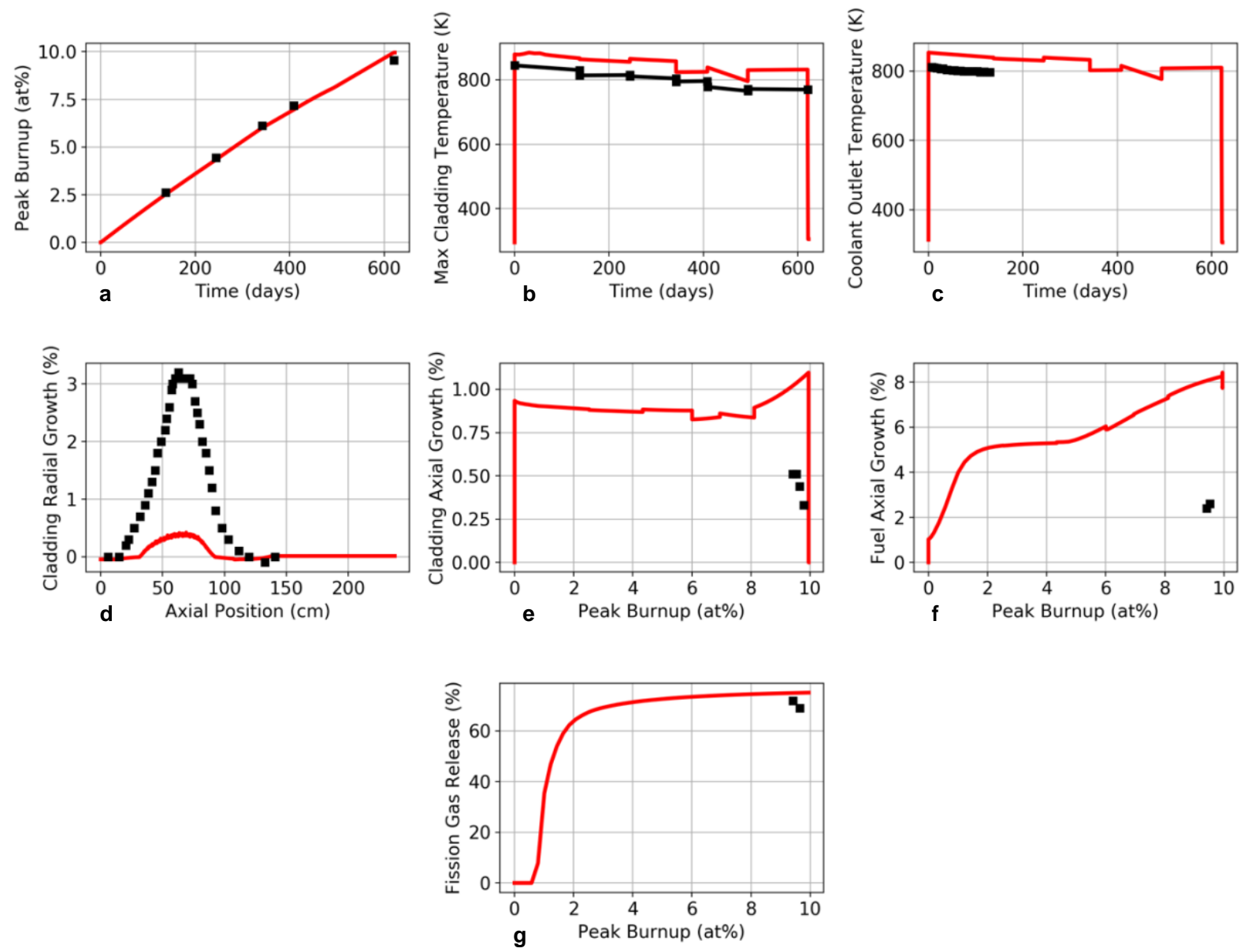

Figure 4. Comparison of BISON simulation results with experimental results for burnup, maximum cladding temperature, coolant outlet temperature, radial and axial growth of the cladding, axial growth of the fuel, and FGR.

The radial growth of the cladding is shown in plot $\mathrm{d}$ shown in Figure 4. The simulation predicts a maximum growth of $0.4 \%$, but the experiment showed radial growth of $3 \%$. The result is highly inaccurate, which suggests missing or incorrect physics in BISON.

Plots e and $\mathrm{f}$ in Figure 4 show the axial growth of the cladding and fuel, respectively. BISON predicts no axial growth in the cladding and $7.8 \%$ axial growth in the fuel. The experiment found $0.33-0.51 \%$ axial growth in the cladding and 2.4-2.6\% axial growth in the fuel. The BISON model is underpredicting cladding axial growth while overpredicting fuel axial growth.

There is also an interesting feature of the fuel axial growth in which the fuel actually grows during cooling. This appears to have been caused by the cladding. The cladding contracted radially during cooling, which puts pressure on the fuel and squeezes it like toothpaste. This behavior is probably an artifact of the frictionless contact model and is not representative of actual fuel slug behavior.

The final comparison between the experiment and benchmark problem is FGR. This is shown in Figure 4, plot $\mathrm{g}$. The result is accurate, much like the burnup calculation. However, since the experimental data were only measured during PIE, it is not clear if the simulation is accurate at all burnups. 


\subsection{DISCUSSION}

The burnup and FGR values calculated by BISON are as accurate as can reasonably be expected. However, since data only exist for the end of the experiment, it is not possible to assess whether the FGR model is generally accurate. To accomplish this, more comparisons are needed at different burnups.

The peak temperatures of the cladding and coolant are reasonably accurate. This is a promising result, but the bias requires further study. Several problems may contribute to the error, including uncertainty in the input parameters and problems in the underlying models. Section 5 presents a sensitivity analysis which is used to determine the extent to which uncertainty in the input parameters may contribute to this result.

The radial and axial growth of the cladding and the axial growth of the fuel are much more problematic. However, upon close inspection, these results may not be as problematic as they appear. Figure 5 shows the cladding radial growth at 600 days, which is prior to the shutdown step of the simulation. Once again it is compared to experimental PIE results, but this time, the simulated radial growth is much higher and more accurate. This suggests that a significant part of the problem is that strain is not permanent in the simulation. There could be a problem in the elastic/inelastic strain components of the D9 cladding model, but the frictionless contact model is also a likely cause. During cooling, the fuel grows axially as the cladding contracts, but if friction were to prevent the fuel from growing, then the cladding would not be able to contract as much, and the radial growth would be permanent.

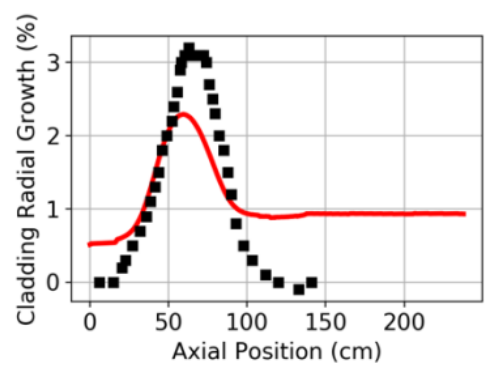

Figure 5. Comparison of experimental radial growth at PIE and simulated radial growth at 600 days and reactor temperature. The simulated radial growth is much closer to the experimental data at full power than during PIE (compare to Figure 4).

Friction could also cause the simulation to overpredict fuel axial growth while underpredicting cladding axial growth. During cooling, the cladding contracts axially and radially. Without friction, the fuel does not exert any force to prevent this, but with friction, the cladding may not be able to fully contract axially. Friction would also put a compressive force on the fuel and may retard its axial growth.

Another potential problem is that BISON does not model fuel-cladding chemical interaction (FCCI). FCCI can cause the fuel and cladding to bond, which would cause more stress in addition to that caused by friction. If the fuel and cladding bond after thermal expansion, then the cladding may be constricted from contracting during cooling, resulting in additional axial growth. Bonding could also force the fuel to expand radially as it becomes restricted in the axial direction. This would further increase the radial growth of the fuel and cladding while decreasing the axial growth of the fuel.

\section{BISON SIMULATION WITH THE FRICTION GAP MODEL}

As mentioned above, BISON works most efficiently with frictionless contact. However, frictionless contact appears to be adversely affecting the simulation results. As described in this section, the 
simulation was adjusted to include friction and was then repeated; the results are compared to those presented in Section 3.

\subsection{SETUP}

The parameters presented in this section were the same as those used in the work described in Section 2, except that a friction coefficient was added. Since the actual coefficient is unknown, coefficients ranging from 0.1 to 0.6 are used in six simulations. The simulations use MOOSE's Augmented Lagrangian Contact model.

\subsection{RESULTS}

Figure 6 shows the dimensional change results of the benchmark problem simulations using friction. The other results are the same as those presented in Section 3. The simulations are shown in gray, while the experimental data are shown in black. Interestingly, the actual value of the coefficient made little difference, even though the cladding's radial growth and fuel's axial growth results are both significantly improved.
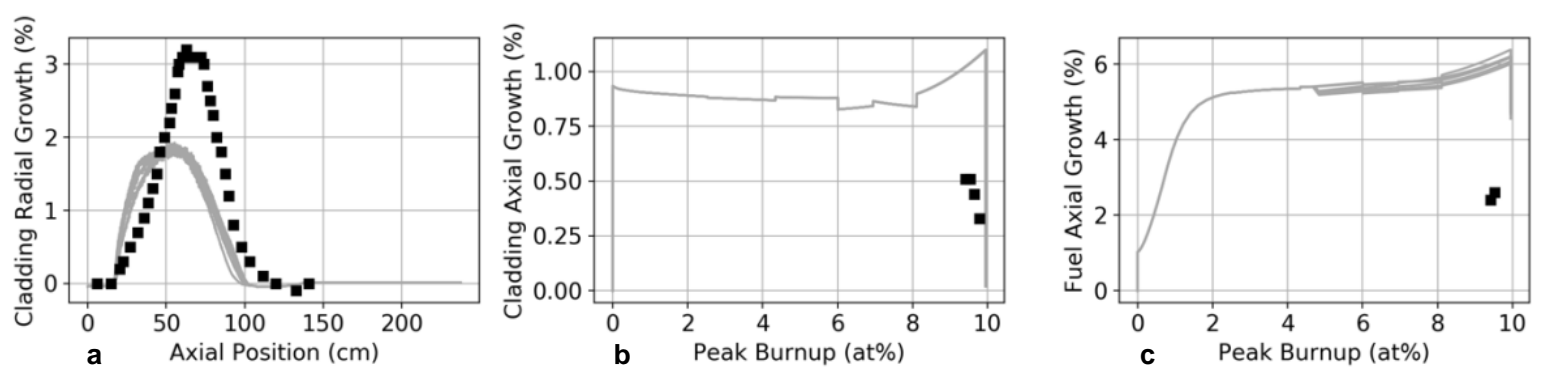

Figure 6. Comparison of BISON simulation results including friction to experimental results. Simulation results are shown in gray, and experimental results are shown in black. The burnup, temperature, and FGR results were not affected by including friction, so those results are not shown here. Since the friction coefficient was unknown, six different friction coefficients were used ranging from 0.1 to 0.6 . However, the value of the friction coefficient did not significantly impact the behavior.

The radial growth of peak cladding with friction was $2 \%$, the cladding axial growth was $0.02 \%$, and the fuel axial growth was $4.7 \%$. The fuel growth that had occurred during cooling (see Figure 4) was no longer observed.

\subsection{DISCUSSION}

The swelling models in BISON were primarily developed using data from EBR-II pins [16]. However, FFTF pins regularly exhibited less relative axial growth, leading some experts to argue axial growth is an end effect which only occurs near the top of the pin [25]. This could also explain why the model overpredicts axial growth. An investigation into this possibility is not possible in the present work. More benchmarks based on EBR-II experiments and additional FFTF experiments will be necessary.

The relative differences between the simulated and experimental dimensional changes were significant, but the absolute differences are also worth noting. The simulated cladding radial growth error was $34 \mu \mathrm{m}$, and the corresponding error in the cladding axial growth was $7 \mathrm{~mm}$. The simulated fuel axial growth error was $20 \mathrm{~mm}$. In absolute terms, the errors were small, so the next question to resolve is whether these errors are relevant for the experiment. The answer to that question is in the design criteria. If the tolerances on the acceptable dimensional changes are small, then the dimensional errors are significant. If there are wide margins of acceptable dimensional changes, then these BISON results should be 
reasonably accurate. In the case of the cladding's radial growth, the experimental growth reduces the coolant channel cross section by $5.3 \%$, whereas the simulated growth reduces the cross section by $3.5 \%$. This amount of error in the simulation is unlikely to significantly affect the results.

Since the axial growth of cladding leads to pin bowing, a $7 \mathrm{~mm}$ difference in the cladding length could significantly affect this behavior. However, BISON does not model pin bowing. Even if the cladding axial growth were correct, BISON could not calculate the amount of bowing it would cause.

The largest effect of the fuel axial growth would likely be in the neutronics effects of the simulation, but once again, BISON does not calculate neutron fluxes, so even with perfectly accurate results, BISON would not necessarily be any more predictive.

Therefore, the addition of friction does improve the accuracy of the dimensional changes predicted by BISON, but there is still substantial relative error. The effects of this error depend on the design criteria being considered.

\section{SENSITIVITY ANALYSIS}

\subsection{SETUP}

To better understand the behavior of the BISON models, a sensitivity analysis was performed on some of the input parameters. First, the parameters being studied were chosen. It would not be feasible to perform a sensitivity analysis on all of the parameters since a BISON input file can contain hundreds. Instead, eight parameters were identified that are both uncertain and that also appear likely to affect the simulation results. The input parameters and the rationales for analyzing them are detailed below:

- Average energy per fission: the INL report [11] lists two different values in two different analyses performed.

- LHR: the power histories used in fuel performance simulations are often simplified and based partially on assumptions; this problem is no exception.

- Plenum thermal conductivity: BISON requires this parameter to be constant, when in fact it varies with temperature.

- Coolant mass flux: Cabell's summary description of FFTF [9], which provides the coolant inlet velocity, was published two years before FFTF began experimental operation. It is unclear whether the velocity is a design parameter, an estimate, or if it was measured during pre-startup testing.

- CTE of the fuel: similar to the plenum thermal conductivity, BISON requires this parameter to be constant, despite actually being a function of temperature.

- Fuel anisotropy factor: because this is a fitting parameter, no experimental data are available to determine its correct value for this fuel composition.

- Fast neutron flux factor: uncertainties in the recorded fluences, burnups, and power history have propagated into this value.

- Cladding swelling rate: BISON's D9 swelling model was developed so recently that this may be the first work in which it has been used.

The LHR and cladding swelling rate were not varied directly. Rather, a unitless multiplier was applied to them to vary the overall effect. This section uses the frictionless baseline simulation from Section 3 because the simulation time is much shorter. A Monte Carlo sensitivity analysis was performed [26] and was repeated 200 times. In each simulation, the parameters listed above were chosen at random from a uniform distribution of the baseline value $\pm 10 \%$. The unitless multipliers applied to the LHR and the cladding swelling rate had values of $1 \pm 0.1$. 


\subsection{RESULTS}

Three methods are used to visualize the results of the sensitivity analyses. First, all of the simulation results are displayed together compared to the experimental data, similar to that depicted in Figure 4. Second, histograms are used to examine the distributions of the PIE simulation results. Third, input parameter to simulation result comparisons are plotted to show which input parameters control and affect which simulation results.

The comparisons to experimental data are shown in Figure 7, in which the simulation burnup fans out around the experimental values. This suggests a high level of sensitivity in the burnup model, such that relatively minor errors in model inputs can have a large effect on the simulation result errors. By contrast, the FGR behavior showed virtually no variation. This suggests that the parameters chosen for this sensitivity study do not have a significant impact on the FGR model in BISON.

The temperatures of the cladding and coolant also show a range of values, and the lower end of the range reaches the experimental temperatures. This adds credibility to the concept that input parameter uncertainties could result in the temperature bias seen in Section 3.

The cladding radial growth and the fuel axial growth were both affected by the input parameters. The effects were not as large as the effects of including friction, but they were still substantial. The cladding axial growth, on the other hand, was not affected at all. Every simulation resulted in $0 \%$ growth.

Figure 8 shows the distribution of simulation results during the sensitivity study. Cladding axial growth data are not included because they had no variation. Even though every input followed a uniform distribution, most results followed normal distributions. This suggests that each result depended on multiple input parameters. The only result that did not appear to follow a normal distribution was the fuel axial growth, which is shown as a long tail in the plot.

For the sake of space, the plots showing the relationships between input parameters and results are not shown here, but they are included in Appendix A. Once again, the cladding axial growth is not included because it had no variation. Burnup, fuel axial growth, and FGR have positive correlations with LHR and negative correlations with energy per fission. The temperatures have positive correlations with LHR and negative correlations with coolant inlet mass flux. Cladding radial growth is correlated with the LHR, the fuel CTE, and the fast flux fission factor. None of the results appear to have strong correlations with the gap thermal conductivity, fuel anisotropy factor, or cladding swelling. 

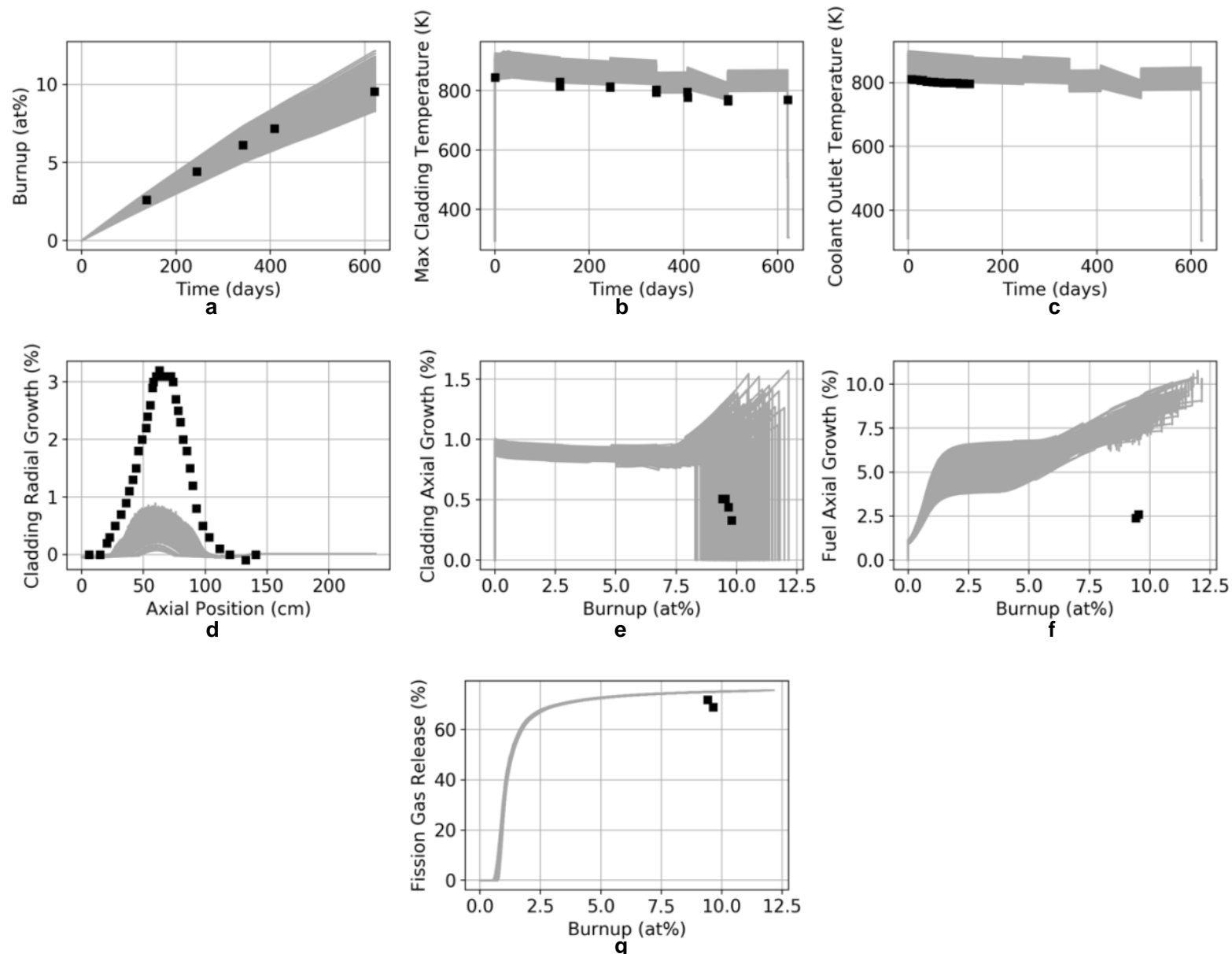

Figure 7. Simulation results of sensitivity analysis. The 200 simulations are plotted as gray lines, and the experimental results are shown in black. 

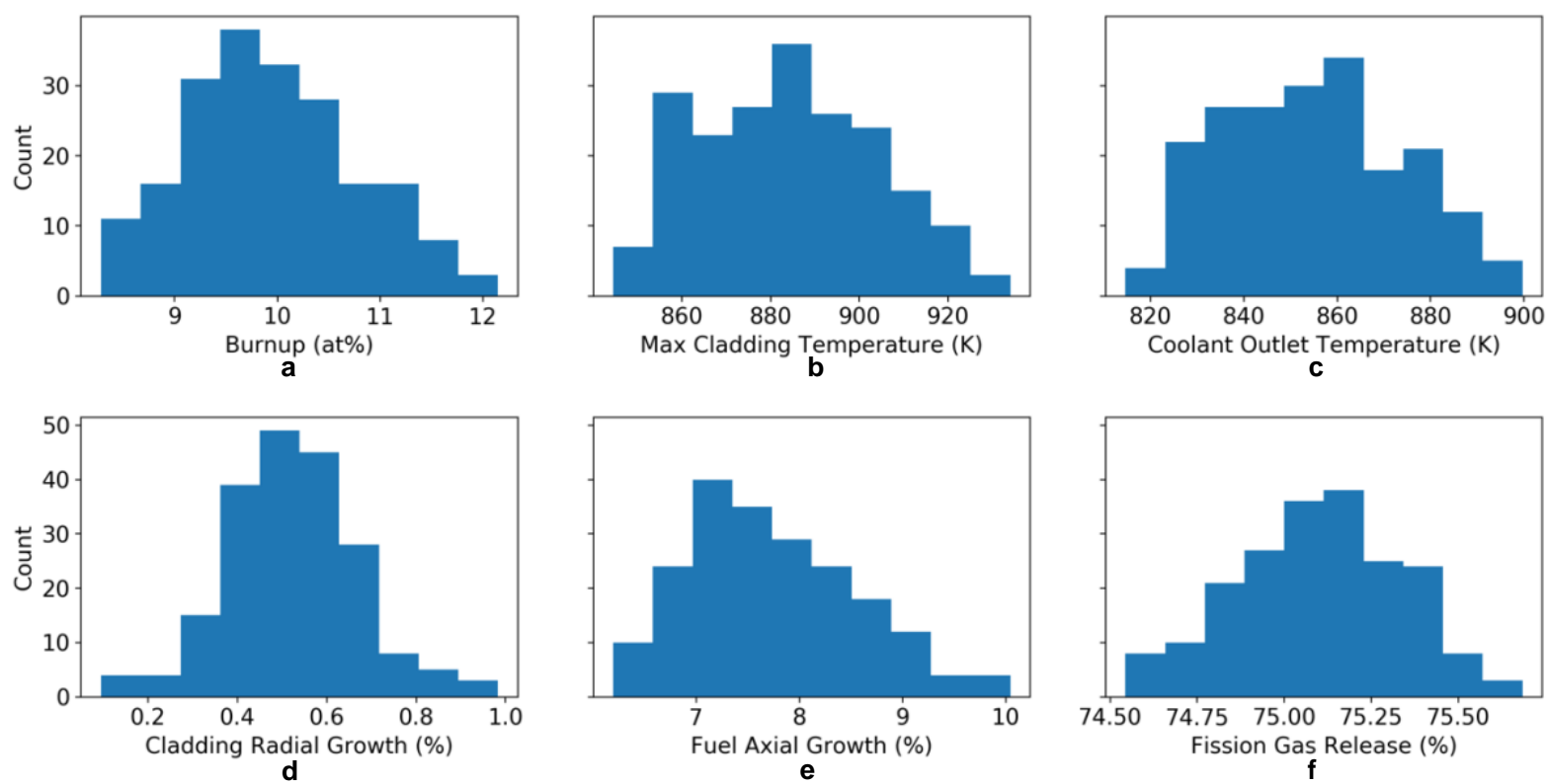

Figure 8. Distributions of the variables from the 200 BISON simulations shown in Figure 7. Altering the variables had no effect on the cladding axial growth, so that distribution is not included here.

\subsection{DISCUSSION}

The fact that fuel axial growth and FGR have the same correlations as burnup is likely because those models depend on burnup. In the case of FGR, burnup has a relatively small effect. Furthermore, since the burnup result in the baseline simulation was accurate, it seems unlikely that input parameter uncertainty plays a large role in the error in the fuel axial growth results. Two possible explanations are (1) the fuel axial growth is controlled by another parameter that was not studied here, or (2) there is a problem in the underlying models. The second explanation is at least part of the issue, because adding friction significantly improves fuel axial growth. Perhaps the addition of FCCI would further improve the result.

By decreasing the LHR and increasing the coolant mass flux, the simulated temperatures were brought into good agreement with the experimental results. However, decreasing the LHR had the simultaneous effect of reducing burnup and growth in the fuel and cladding. Still, it appears that a significant portion of the temperature bias could be caused by input parameter uncertainty.

\section{CONCLUSIONS AND FUTURE WORK}

In this work, a benchmark problem based on the IFR-1 experiment was developed for metallic fuel performance simulations. The problem was implemented and studied using the BISON fuel performance code. The results of the simulation show that burnup and FGR models in BISON are able to accurately replicate experimental results. Temperature calculations are about $42 \mathrm{~K}$ higher in the simulation than in the experiments, which may be a result of input parameter uncertainty. Dimensional changes, including cladding radial growth, cladding axial growth, and fuel axial growth, are not accurate relative to experiment results, but since the experimental changes are small, the absolute error of the simulations in these respects are small. 
The cladding radial growth and fuel axial growth can be significantly improved by adding friction to the model. However, the model is not sensitive to the value of the friction coefficient. Neither friction nor adjusting input parameters had a significant effect on cladding axial growth.

The recommendations for near-term BISON development are to find a way to include an FCCI model in the code and to investigate the D9 swelling model to ensure that it is behaving as intended. For future model development, finding additional data for coolant inlet mass flux would significantly reduce the uncertainty of the temperature calculations. Once these changes are made, any improvements to model performance can be quantified by running the benchmark problem again and comparing the results to those found in this work.

\section{ACKNOWLEDGMENTS}

This work was funded by the US Department of Energy Office of Nuclear Energy (DOE-NE) Versatile Test Reactor project. The authors wish to thank Stephen Novascone, Al Casagranda, and Adam Zabriskie of the INL BISON development team and Alexander Lindsay of the INL MOOSE development team for their valuable input in BISON fuel performance models in metallic fuels. The authors also want to acknowledge Topher Mathews at Los Alamos National Laboratory, who developed the D9 models and implemented them and other improvements in BISON. Lastly, the authors wish to thank Doug Crawford and Doug Porter for sharing their knowledge and experiences with metallic fuels in general and the IFR-1 experiment in particular.

\section{REFERENCES}

[1] H. S. Aybar and P. Ortega, "A review of nuclear fuel performance codes," Progress in Nuclear Energy, pp. 127-141, 2005.

[2] D. Olander, "Nuclear fuels - Present and future," Journal of Nuclear Materials, vol. 389, no. 1, pp. $1-22,2009$.

[3] Y. I. Chang, "Technical Rationale for Metal Fuel in Fast Reactors," Nuclear Engineering and Technology, vol. 39, no. 3, pp. 161-170, 2007.

[4] US Department of Energy, "Versatile Test Reactor: World-Class R\&D Enabled by Fast Neutrons," October 2019. [Online]. Available: https://www.energy.gov/sites/prod/files/2019/11/f68/1950625_VTR_R7_0.pdf. [Accessed 10 March 2020].

[5] US Department of Energy, "Secretary Perry Launches Versatile Test Reactor Project to Modernize Nuclear Research and Development Infrastructure," 28 February 2019. [Online]. Available: https://www.energy.gov/articles/secretary-perry-launches-versatile-test-reactor-project-modernizenuclear-research-and. [Accessed 10 March 2020].

[6] Third Way, "Keeping Up with the Advanced Nuclear Industry," 8 February 2018. [Online]. Available: https://www.thirdway.org/graphic/keeping-up-with-the-advanced-nuclear-industry. [Accessed 10 March 2020].

[7] C. E. Till, Y. I. Chang and W. H. Hannum, "The integral fast reactor - an overview," Progress in Nuclear Energy, vol. 31, pp. 3-11, 1997.

[8] Hanford Site, "400 Area / Fast Flux Test Facility," [Online]. Available: https://www.hanford.gov/page.cfm/400areafftf. [Accessed 11 March 2020].

[9] C. P. Cabell, "A Summary Description of the Fast Flux Test Facility," Hanford Engineering Development Laboraotory Report HEDL-400, Hanford, Washington, 1980. 
[10] H. Tsai and L. A. Neimark, "Irradiation performance of full-length metallic IFR fuels.," Argonne National Laboratory Report ANL/CP-74935, Argonne, Illinois, 1992.

[11] D. L. Porter and H. Tsai, "Full-length Metallic Fast Reactor Fuel Pin Test in FFTF (IFR-1)," Idaho National Laboratory INL/EXT-12-25550, Idaho Falls, Idaho, 2011.

[12] D. L. Porter and H. Tsai, "Full-length U-xPu-10Zr (x=0, 8, 19wt.1\%) fast reactor fuel test in FFTF," Journal of Nuclear Materials, vol. 427, no. 1, pp. 46-57, 2012.

[13] J. D. Galloway, C. Mathews and C. Unal, "Enhancements to BISON U-Zr Metallic Fuel X447 Example Problem," Argonne National Laboratory ANL-NSE-3, Los Alamos, New Mexico, 2016.

[14] Idaho National Laboratory, "BISON Manual," Idaho National Laboratory, [Online]. Available: https://mooseframework.org/bison/. [Accessed 27 March 2020].

[15] K. M. Cunningham, J. J. Powers and R. A. Lefebvre, "Modeling the IFR-1 Experiment: A BISON Metallic Fuel Benchmark," Oak Ridge National Laboratory ORNL/TM-2019/1270, Oak Ridge, Tennessee, 2019.

[16] G. L. Hofman, M. C. Billone, J. F. Koenig, J. M. Kramer, L. D. B. Lambert, L. Leibowitz, Y. Orechwa, D. R. Pedersen, D. L. Porter, H. Tsai and A. E. Wright, "Metallic Fuels Handbook," Argonne National Laboratory ANL-NSE-3, Argonne, Illinois, 1989.

[17] D. E. Janney, "Metallic Fuels Handbook," Idaho National Laboratory INL/EXT-15-36520, Idaho Falls, Idaho, 2018.

[18] A. Casagranda, BISON Metallic Fuel/VTR Training, Oak Ridge, Tennessee, 2020.

[19] R. G. Pahl and R. S. Wisner, "Steady-state Irradiation Testing of U-Pu-Zr Fuel to >18\% Burnup," Argonne National Laboratory CONF-900804-25, Argonne, Illinois, 1990.

[20] J. K. Hales, R. L. Williamson, S. R. Novascone, G. Pastore, B. W. Spencer, D. S. Stafford, K. A. Gamble, D. M. Perez and W. Liu, "Bison theory manual the equations behind nuclear fuel analysis," Idaho National Laboraotory INL/EXT-13-29930, Idaho Falls, Idaho, 2016.

[21] H. Savage, "The heat content and specific heat of some metallic fast-reactor fuels containing plutonium," Journal of Nuclear Materials, vol. 25, no. 3, pp. 249-259, 1968.

[22] Y. S. Kim and T. W. Cho, "Thermal conductivities of actinides (U, Pu, Np, Cm, Am) and UraniumAlloys (U-Zr, U-Pu-Zr, and U-Pu-TRU-Zr)," Journal of Nuclear Materials, vol. 445, no. 1-3, pp. 272-280, 2014.

[23] J. K. Fink and L. Leibowitz, "Thermodynamic and transport properties of sodium liquid and vapor," Argonne National Laboratory ANL/RE-95/2, Argonne, Illinois, 1995.

[24] B. W. Spencer, J. W. Peterson, W. Jiang, Y. Liu, S. Veeraraghavan and A. Casagranda, "Bison contact algorithm improvements in support of pellet cladding mechanical interation modeling," Idaho National Laboratory INL/EXT-17-43399, Idaho Falls, Idaho, 2017.

[25] J. M. Harp, L. Capriotti, S. L. Hayes and D. L. Porter, "Testing Fast Reactor Fuels in a Thermal Reactor: A Comparison Report," Idaho National Laboratory INL/EXT-17-41677, Idaho Falls, Idaho, 2017.

[26] M. H. Kalos and P. A. Whitlock, Monte Carlo Methods, Wiley VHC, 2008.

[27] D. C. Crawford, D. L. Porter and S. L. Hayes, "Fuels for sodium-cooled fast reactors: US perspective," Journal of Nuclear Materials, vol. 371, no. 1-3, pp. 202-231, 2007. 
APPENDIX A.

COMPARISONS OF INPUT PARAMETERS TO SIMULATION RESULTS DURING SENSITIVITY ANALYSIS 



\section{APPENDIX A. COMPARISONS OF INPUT PARAMETERS TO SIMULATION RESULTS DURING SENSITIVITY ANALYSIS}
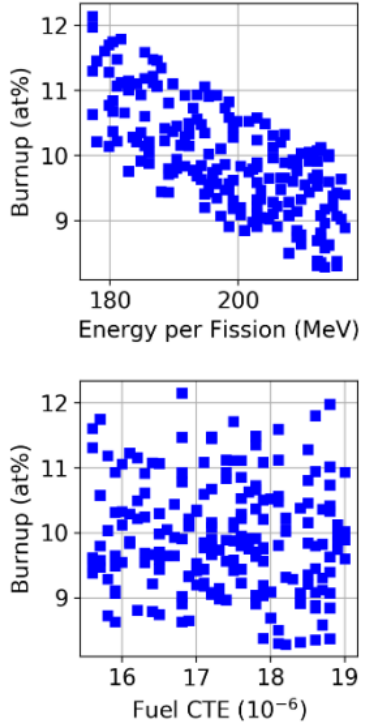
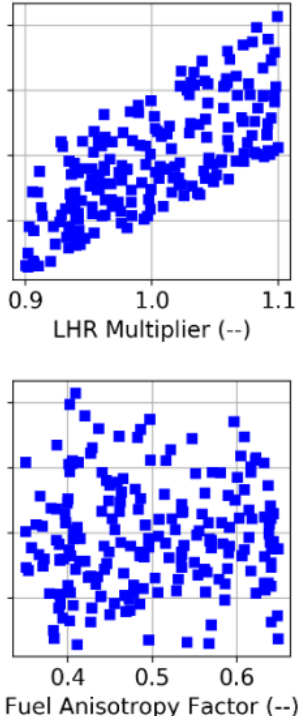

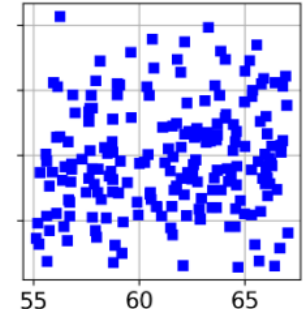

Gap Thermal Conductivity (W/m K)

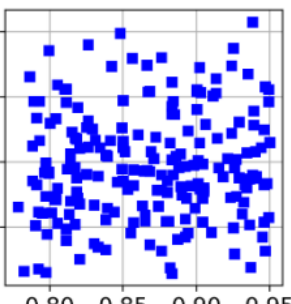

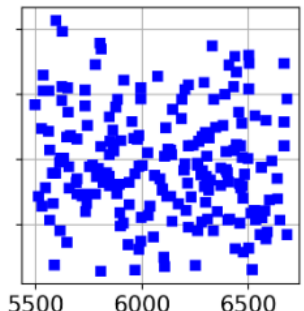

Coolant Mass Flux $\left(\mathrm{kg} / \mathrm{m}^{2} \mathrm{~s}\right)$

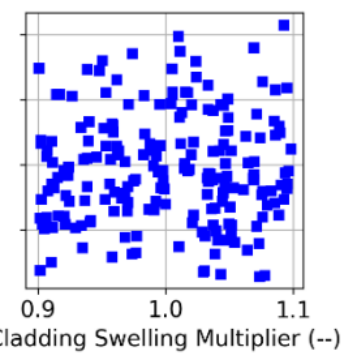

Figure 9. Comparison of input parameters and burnup results for the sensitivity analysis.
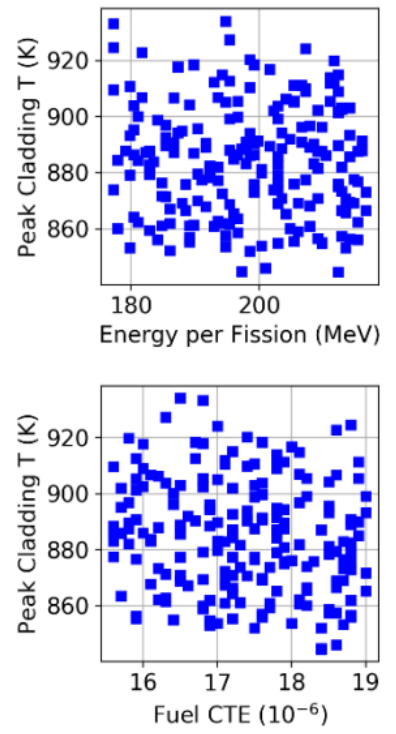
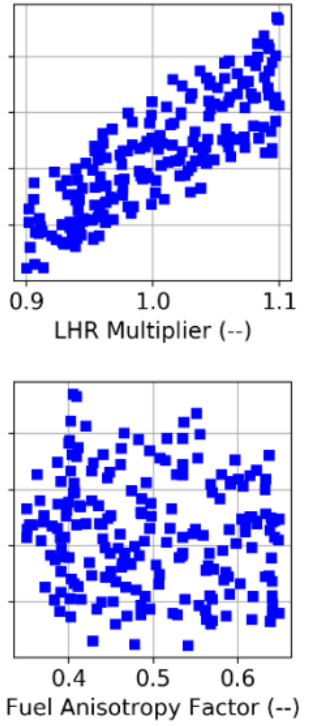

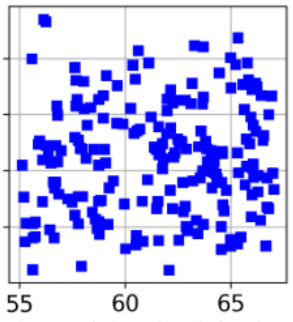

Gap Thermal Conductivity (W/m K)
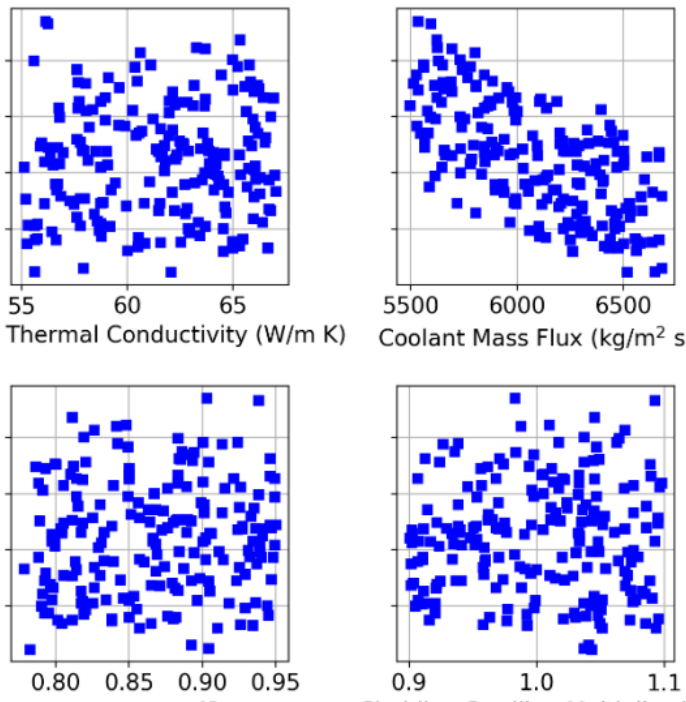

Fast Flux Factor ( $10^{15} \mathrm{n} / \mathrm{W} \mathrm{m} \mathrm{s}$ )

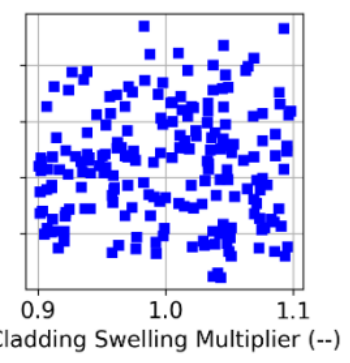

Figure 10. Comparison of input parameters and peak cladding temperature results for the sensitivity analysis. 

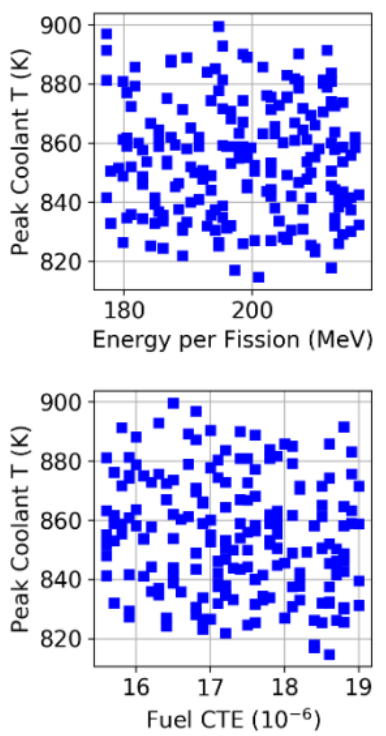
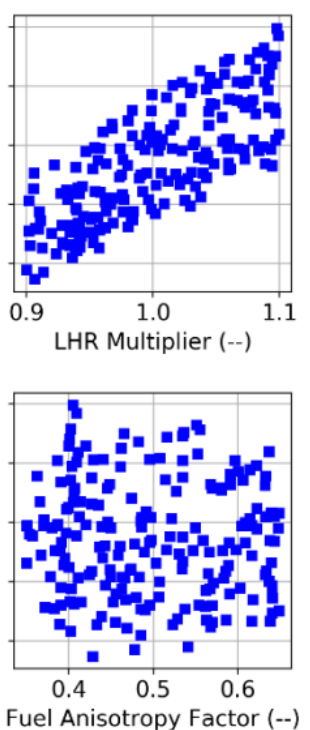

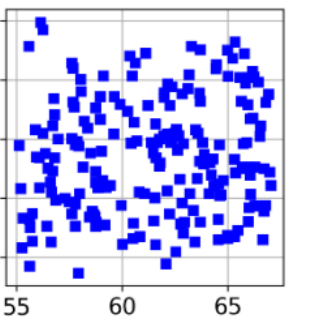

Gap Thermal Conductivity (W/m K)

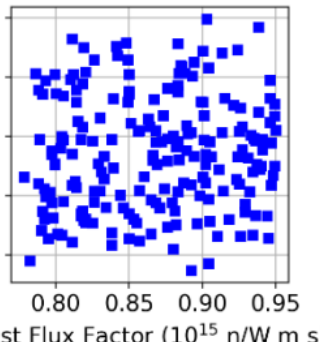

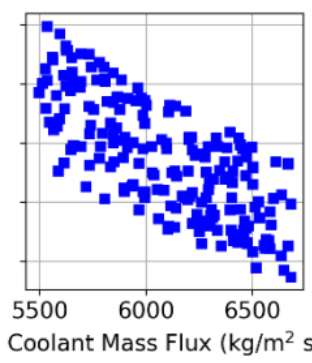

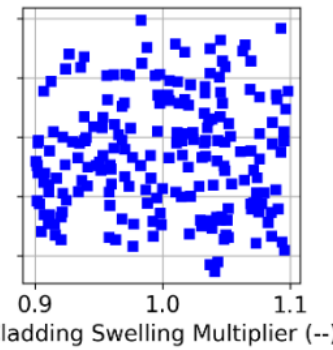

Figure 11. Comparison of input parameters and peak coolant temperature results for the sensitivity analysis.
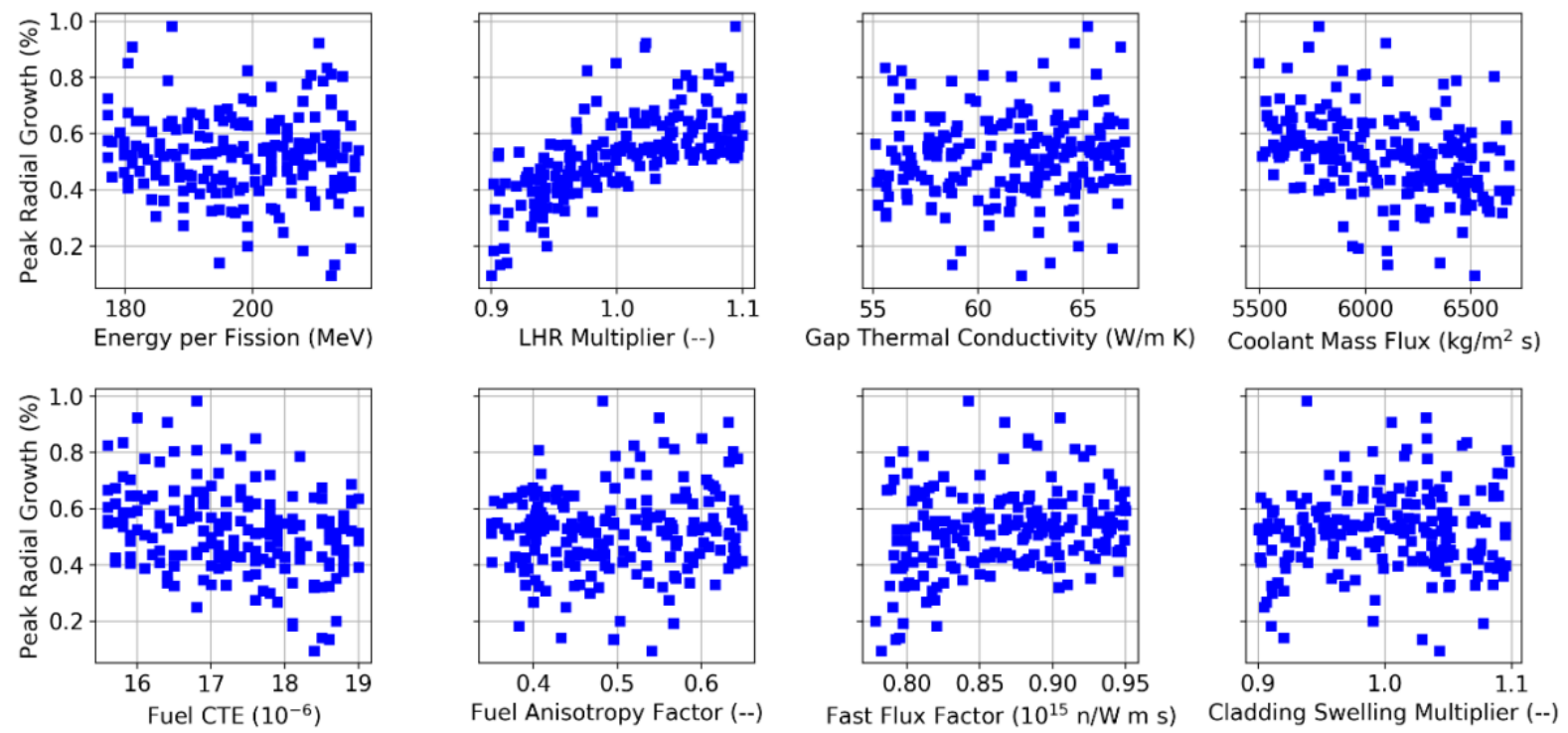

Figure 12. Comparison of input parameters and cladding radial growth results for the sensitivity analysis. 

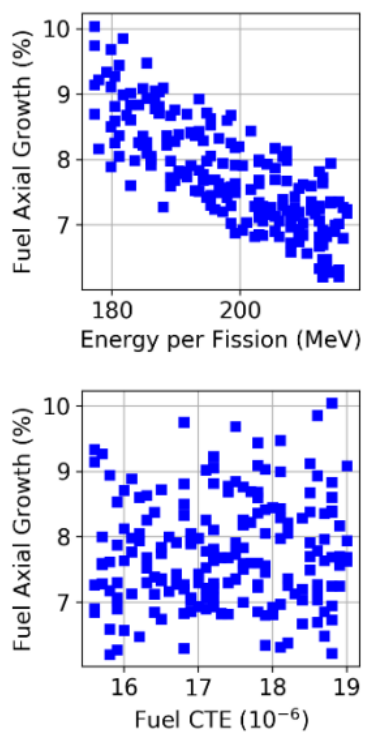
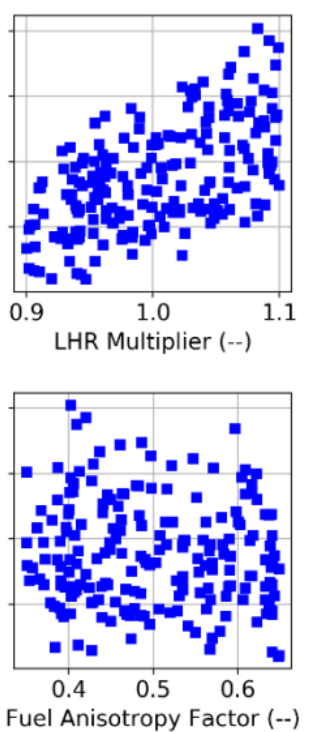

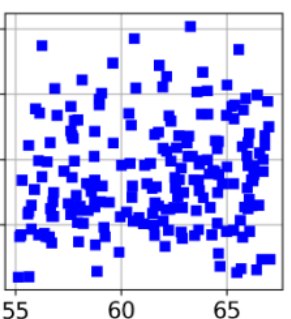

Gap Thermal Conductivity (W/m K)

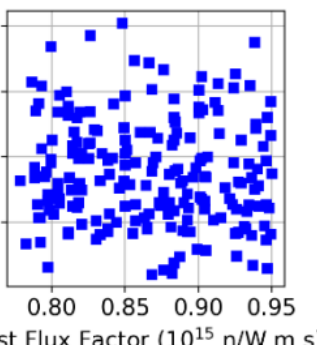

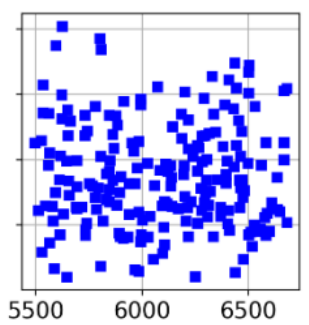

Coolant Mass Flux $\left(\mathrm{kg} / \mathrm{m}^{2} \mathrm{~s}\right)$

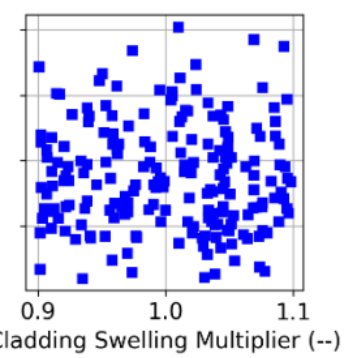

Figure 13. Comparison of input parameters and fuel axial growth for the sensitivity analysis.
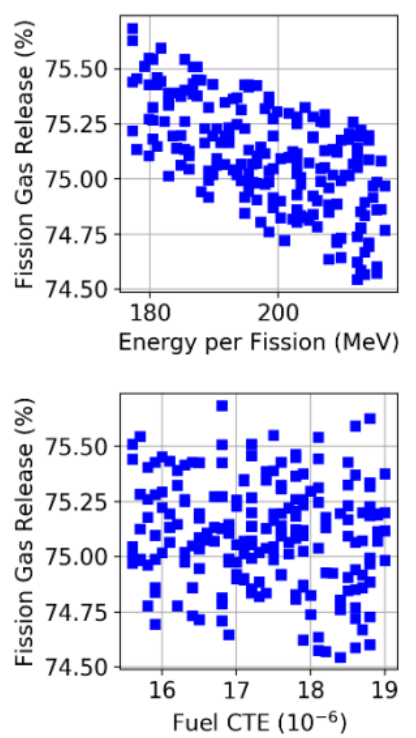
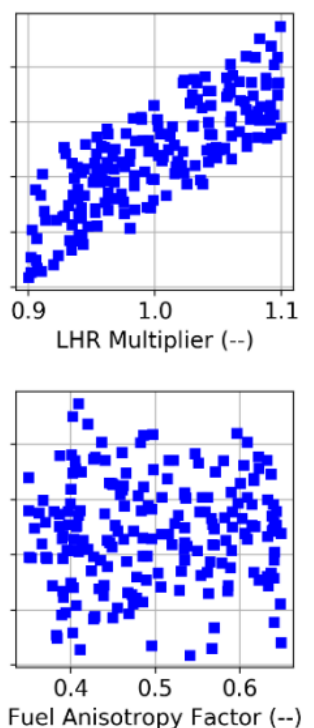

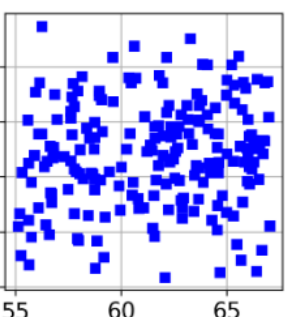

Gap Thermal Conductivity (W/m K)

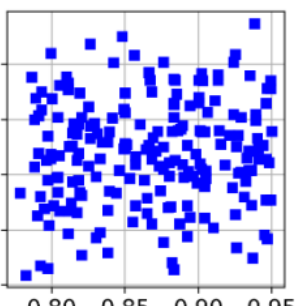

Fast Flux Factor (1015 $\mathrm{n} / \mathrm{W} \mathrm{m}$

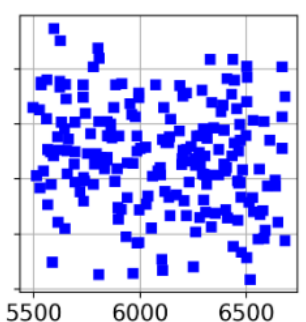

Coolant Mass Flux $\left(\mathrm{kg} / \mathrm{m}^{2} \mathrm{~s}\right)$

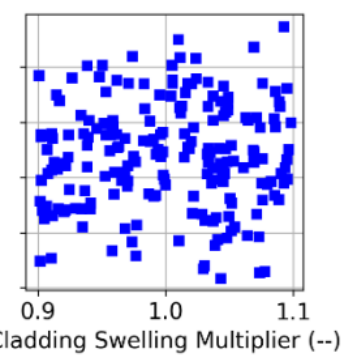

Figure 14. Comparison of input parameters and FGR results for the sensitivity analysis. 